University of Rhode Island

DigitalCommons@URI

Open Access Dissertations

1976

\title{
The Effects of Self-Imposed and Externally Imposed Rewards of Children's Intrinsic Motivation
}

Douglas Lee Schooler

University of Rhode Island

Follow this and additional works at: https://digitalcommons.uri.edu/oa_diss

\section{Recommended Citation}

Schooler, Douglas Lee, "The Effects of Self-Imposed and Externally Imposed Rewards of Children's Intrinsic Motivation" (1976). Open Access Dissertations. Paper 1076.

https://digitalcommons.uri.edu/oa_diss/1076

This Dissertation is brought to you for free and open access by DigitalCommons@URI. It has been accepted for inclusion in Open Access Dissertations by an authorized administrator of DigitalCommons@URI. For more information, please contact digitalcommons-group@uri.edu. 
THE EFFECTS OF SELF-IMPOSED AND EXTERNALLY IMPOSED REWARDS OF CHILDREN'S INTRINSIC MOTIVATION BY

DOUGLAS LEE SCHOOLER

A DISSERTATION SUBMITTED IN PARTIAL FULFILLMENT OF THE REQUIREMENTS FOR THE DEGREE OF DOCTOR OF PHILOSOPHY

IN

PSYCHOLOGY 


\section{Abstract}

An experiment was designed to compare the effects of self-imposed, externally imposed, and a no reward control, on children's interest in both a high and low listening task. A hypothesis grounded in personal control theory predicted that self-imposed rewards would increase subsequent task interest, whereas externally imposed reward would interact with initial task interest and would yield a decrease in interest for the high interest task and an increase in interest for the low interest task. A secondary hypothesis predicted that children would self-reward with greater magnitude on the low interest task. The subjects, 48 boys and 48 girls from the fifth and sixth grades, were asked to listen to either Music or Voice tapes in one of the three reward conditions. The primary dependent measure was the amount of time they continued to listen to the tape during a free-time observation period. Results did not support either hypothesis. The only significant effect of tangible reward was an observed increase in subsequent listening time for girls who were externally rewarded for listening to music. Șelf-reward magnitude did not vary significantly between the high and low interest tasks. However, boys and girls differed significantly in their self-reward behavior across trials. Results are discussed in terms of the efficacy of intended manipulations. Suggestions for future research strategies are offered. 


\section{Acknowledgments}

So many people have contributed to this work, in so many ways. Thanks to Stephen L. O'Keefe, major professor and friend, who guided me with a gentle hand through my years of graduate study. I will always be grateful for having had the opportunity to work under Steve's creative and honest tutelage.

To my Committee - Marcia Flugsrud, John Stevenson, and Henry Biller - goes my deep appreciation for their continued interest in my professional and personal growth.

This research could not have been conducted without the assistance of the public schools of Middletown and Narragansett, Rhode Island. Particular thanks go to Mike Pinto and Dave Hayes, and the teachers and students of the fifth and sixth grades. Thanks also to the Audio Visual Department and the Computer Services facility at the University of Rhode Island for their generous assistance.

A great debt of gratitude is owed to the faculty of the Psychology Department, so many of whom extended themselves. to offer help and advice. Special thanks to Wayne Velicer for his patient help with statistics and ideas; to Nelson Smith, for his assistance with the equipment and design of the study; and to William T. Vosburgh, for making so many things happen for me during my stay, and for being there when I needed him.

It is with a great sense of appreciation that I thank the students of the Psychology Department, and the School Psychology Program in particular, for their support and caring in the best and worst of times. 
Thanks especially to Max Alovisetti, Ann Zartler, and Tom Comiskey, and Al Kataja, fellow members of "the club," and to Charlie Pascewicz, for the many hours of rapping about this research.

Without the support and love of my family, given so freely over these uncertain years, I would not be in the place that I am. To all of you - Martha, Seymour, Ann, Abe, Steve, David, Barry and Glenda thanks.

To Barbara, for everything and always, I dedicate this work. 


\section{Preface}

This thesis has been prepared in manuscript style, and in accordance with the specifications set forth in the style manual of the American Psychological Association. Two exceptions to APA guidelines should be noted. First, the tables that are discussed in the text have been placed near the appropriate part of the text rather than at the end, and second, the titles of figures appear on the figures themselves, rather than on a separate sheet. 


\section{Contents}

$\underline{\text { Page }}$

ABSTRACT. . . . . . . . . . . . . . . . . ii

ACKNOWLEDGEMENTS. . . . . . . . . . . . . . . . . . iii

PREFACE . . . . . . . . . . . . . . . . . . v

LIST OF TABLES. . . . . . . . . . . . . . . . . vii

LIST OF FIGURES . . . . . . . . . . . . . . . . ix

Introduction. . . . . . . . . . . . . . . . . . . 1

Overview of the study . . . . . . . . . . . . . 5

Hypotheses and predictions. . . . . . . . . . . . 6

Method. . . . . . . . . . . . . . . . 7

Results . . . . . . . . . . . . . . . 17

Discussion. . . . . . . . . . . . . . 38

References. . . . . . . . . . . . . . . 49

Appendix A: Literature review. . . . . . . . . 51

Appendix B: Pilot studies. . . . . . . . . . 82

Appendix C: Analysis of variance summary tables. . . . 91

Appendix D: Post-experimental questionnaire. . . . . . 98

Appendix E: Raw data . . . . . . . . . . 101

Appendix F: Bibliography . . . . . . . . . 105 


\section{List of Tables}

Table number

$\underline{\text { Page }}$

1. Means and standard deviations for free-time

listening scores. . . . . . . . . . . 18

2. Means and standard deviations of self-reward

scores for each trial . . . . . . . . . . 23

3. Means and standard deviations for each trial for

numbered circles taken by control group . . . . . . 26

4. Correlations of timemon scores with total of

numbered circles. . . . . . . . . . . . 28

5. Correlations of time on scores and monetary

reward scores for each sex. . . . . . . . . 29

6. Percent of students responding in each category

to Question 3... . . . . . . . . . . . 32

7. Percent of students responding in each category

to Question 4... . . . . . . . . . . . . 32

8. Number of Yes and No responses to Question 6. . . . 34

9. Number of responses in each category for Question 8 . 36

10. Correlations among time-on scores and responses

to Questions 3 and 4. . . . . . . . . . . . 37

11. Studies investigating the effects of rewards

on intrinsic motivation . . . . . . . . . . . 70

12. Percent of students ranking tasks Best or Worst

in pilot study. . . . . . . . . . . . . . 85

13. Percent of students ranking each task category

Best or Worst . . . . . . . . . . . . 88

14. Percent of students rating each task category

from Very Good to Very Bad. . . . . . . . . . 89

15. Analysis of variance for free-time listening scores - 92

16. Analysis of variance for self-reward scores . . . . 93

17. Analysis of variance for numbered circles taken

by control group. . . . . . . . . . . . . . 94 
18. Analysis of variance for Question 1. . . . . . . 95

19. Analysis of variance for Question 4. . . . . . . 96

20. Analysis of variance for Question 7. . . . . . . 97 


\section{List of Figures}

Figure number

$\underline{\text { Page }}$

1. Mean number of seconds of free-time listening

for the Music condition . . . . . . . . . . . . . 19

2. Mean number of seconds of free-time listening

for the Voice condition . . . . . . . . . . . 20

3. Means of self-reward scores for each sex at

each trial. . . . . . . . . . . . . . 24

4. Mean number of seconds of free-time 1istening

for Music and Vocie... . . . . . . . . . 42 


\section{Introduction}

It is wel1 known that rewards (e.g., gold stars, tokens, praise) tend to have positive effects on quantitative and qualitative aspects of task performance. In recent years, however, a number of studies have investigated, and documented to a degree, an unintended side effect of reward programs, namely, a decrease in interest when rewards are no longer available (Calder \& Staw, 1975; Deci, 1971, 1972;

Lepper, Greene, \& Nisbett, 1973; Lepper \& Greene, 1975; Ross, 1975). Specifically, when children have been rewarded for doing something in which they already have an interest, their interest has been observed to decrease to below baseline levels after the rewards are no longer supplied. These findings have broad practical implications for many societal institutions, including the family, the school, and the world of work.

The above studies have helped to generate controversy regarding the validity and interpretation of the findings (Ford \& Foster, 1976; Levine \& Fasnacht, 1974, 1976; Reiss \& Sushinsky, 1975). The increasingly maligned technique of the token economy (Krasner, 1976) has been caught in the emotional crossfire. That well designed token programs deal exclusively with low frequency target behaviors is a point that is often ignored in critical speculation.

For most educators, an important goal of schooling is for the student to become exposed to an interested in the subject matter such that the student will continue to develop skills and expand knowledge when outside the immediate confines of the school building. Educators strive to develop a love of learning in general, and 
positive feelings and behavior towards as much of the specific subject matter as possible. That is, there appears to be a concern to maintain or increase a student's intrinsic motivation (i.e., motivation to perform an activity for its own sake, rather than for extrinsic consequences) toward content areas. Do. rewards sometimes interfere with this effort?

Rewards have been extensively used by teachers over the years as a punp priming procedure to motivate the student initially, in the hope that he or she comes to enjoy and perform the activity for its own sake. Such procedures can be appropriate when a particular activity is either uninteresting initially or appears to have little relevance and meaning for the student at first contact. Rewards in this case often have the desired effect. However, what about the case in which the student comes to the activity with a strong interest to perform? It may be that under these circumstances, as the above studies suggest, externally imposed rewards may actually undermine children's interest in an activity. That is, rewards may turn an initially interesting activity into one that is perceived as work, in the sense of drudgery.

Another area of psychology that has enjoyed increasing conceptual and experimental attention in recent years is that of self control and a component process known as self-reinforcement (Goldfried \& Merbaum, 1973; Thoresen \& Mahoney, 1974). Skinner (1953) describes several ways in which individuals can come to control their own behavior. One such process, termed self-reinforcement, involves the contingent selfadministration of reward or punishment in the absence of external con- 
trol. Following Skinner's (1953) conceptualization, the notion of self-reinforcement has been operationalized in various ways and has been investigated as a process and as a dimension of personality with both children and adults (Bandura, 1971; Masters \& Mokros, 1974). Self-reward procedures as behavior change tools are gaining in popularity. (Thoresen \& Mahoney, 1974) and have been shown to be effective in applied settings. For example, Lovitt \& Curtis (1969) found that a 12 year old student's productivity was actually greater when he self-rewarded than when he was rewarded by the teacher. In view of such potential effectiveness, it is predicted that selfreward programs will be increasingly employed, if for no other reason than convenience value and ease of administration. Se1f-reward programs allow the teacher to delegate the difficult task of observing and rewarding to the children themselves. The teacher can then spend valuable time as an educator and resource person instead of primarily a dispenser of rewards and punishments. There is insufficient research examining the effects of self-administered reward with respect to a person's interest in an activity. Is self-reward associated with a subsequent decrease in interest?

The area of personal causation and locus of causality provides some theoretical structure to the question of whether self-reward procedures tend to foster a decrease in interest. de Charms (1968) stresses the importance of a person's feelings of efficacy with respect to producing changes in his or her environment. Implicit in the de Charms discussion are the dysfunctional consequences of feeling like a Pawn (weak, passive, manipulated) rather than an Origin (strong, 
dynamic, in contro1). Seligman (1975) provides evidence for the ma1adaptive consequences of the feeling of helplessness, which range from performance deficits on experimental tasks, to depression and death. Even uncontrolled positive consequences have been shown to have negative effects on the organism (Seligman, 1975).

Because of the differences in the locus of causality, there is reason to suspect that self-reward and external reward procedures will be perceived differently by individuals, and will, therefore, have different behavioral consequences. The present study is designed to compare the effects of self-imposed and externally imposed rewards on task interest. 


\section{Overview of the study}

The central question of the present study is "Do self-imposed rewards, externally imposed rewards, and a no reward control condition have differential effects on children's interest in an activity?" Subjects received experimental treatments according to the following factorial design:

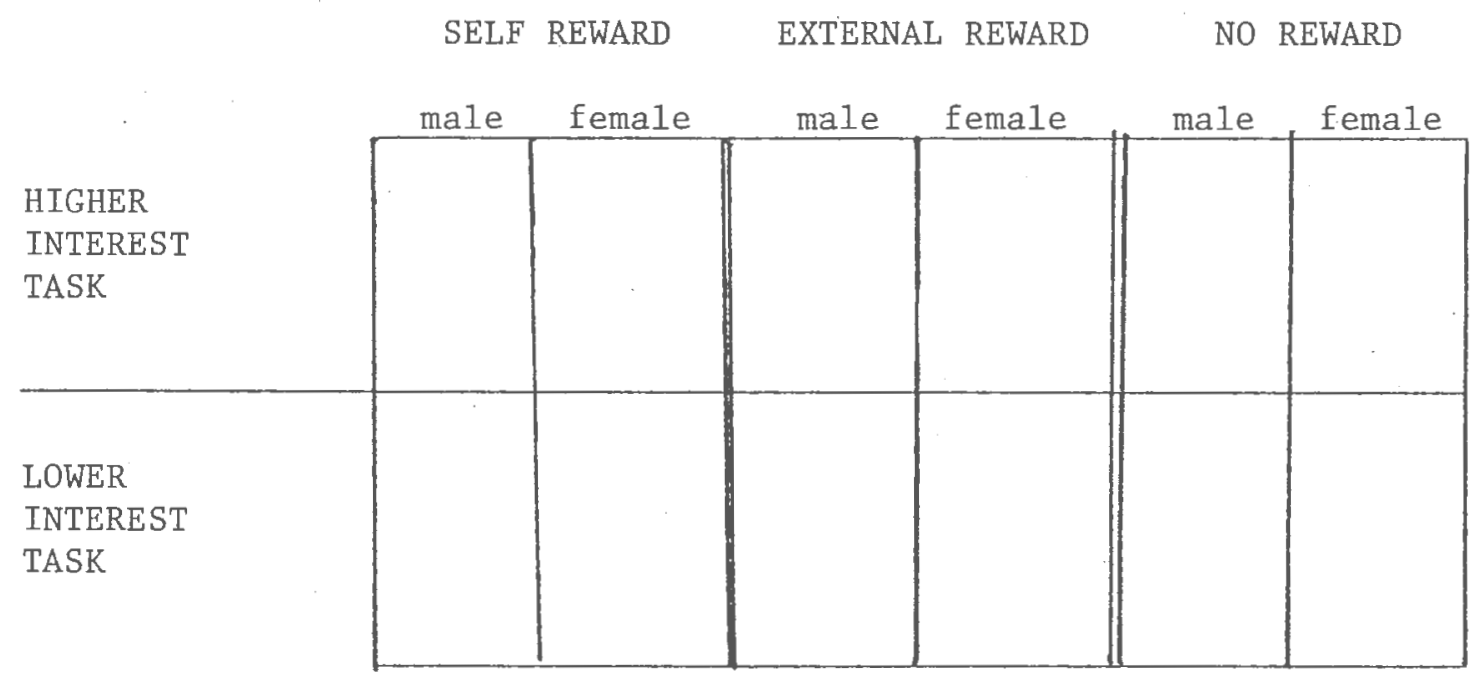

In summary, a three factor design was employed. Each factor is described as follows: (a) Reward condition. Subjects either decided the magnitude of their reward for themselves (self-reward), received the same reward magnitude as a yoked subject in the self-reward condition (external reward), or received no tangible reward. (b) Sex. An equal number of males and females were used. (c) High versus low interest tasks. Listening to music was the high interest task, and a repetitive recording of the human voice served as the low interest task. 


\section{Hypotheses and predictions}

1. The degree of perceived control of rewards affects a person's affective and cognitive orientation towards an activity. The greater the perceived control of rewards, the more positive the affect and the more favorable will be the cognitions towards the activity. Therefore, it is predicted that for a high interest activity:

la. Self imposed tangible rewards will yield higher interest scores than both an external reward and control condition. 1b. Externally imposed rewards will yield lower interest scores than the no reward control condition.

For tasks of low interest it is predicted that:

1c. Self imposed rewards will yield greater interest scores than externally imposed rewards or a no reward control.

1d. Externally imposed rewards will yield greater interest scores than a no reward control.

2. Magnitude of self-reward is inversely related to task interest value. The higher the initial task interest, the lower will be the magnitude of self-reward. It is predicted that:

2a. The self-reward scores for the high interest task will be lower than the self-reward scores for the low interest task. Because there is no theoretical support for hypotheses with regard to sex differences, no specific predictions are made. 


\section{Method}

Subjects

The initial subject pool consisted of approximately 150 children who comprised the entire 5 th and 6 th grades of small coastal town in Southern Rhode Island. Permission slips were distributed to all classes save one, which was to be held in reserve in the event that not enough subjects were obtained. Ultimately, this class would be used also. The first wave of permission slip returns contained 65 affirmative replies. The remainder were returned during the course of the study. Overall, 104 affirmative replies were received; out of this pool, 48 boys and 48 girls were selected for participation in the study.

Assignment to groups Subjects were randomly assigned to experimental treatment groups using a table of random numbers. Children's names were alphabetized and each name was given a number. A subject was assigned to a group as his or her number came up in the random sequence. Groups were filled consecutively, from left to right on the design grid. The foregoing procedure was employed for the first group of 65 permission slip returns. The remaining subjects were assigned to groups as their permission slips were returned.

Order of subjects. The limitation on true randomness was that a given self-reward subject had to be run before his or her yoked partner in the external reward condition for the purpose of yoking reward magnitude from trial to trial. The order of subjects for a day was determined by lottery. Slips were drawn, each representing 
a treatment group, with the exception that an external reward subject always followed directly after the yoked self-reward partner.

\section{Apparatus}

Audio. High quality cassette tapes were used for playback on a portable recording machine of excellent fidelity. Altogether, six practice tapes and six experimental tapes were prepared. Each practice tape contained one minute of material that was similar to, but not identical with, that which was recorded on a matching experimental tape. Experimental tapes consisted of 5 one minute segments of either music or voice, thus creating five listening trials. Following the one minute trials were 3 five minute segments, each segment an exact duplicate of that which was presented to the subject during the trials, for listening during the free time observation period.

A continuous contact button was attached to the tape recorder via the remote jack such that the machine operated only when the button remained depressed. The button (非71PBI, Micro Switch Co.) measured $2 \mathrm{~cm}$. at the diameter and required very little pressure for contact. A standard laboratory timer was wired to the button so that the time the button was depressed could be recorded automatically and unobtrusively.

Reward board. A board measuring $75 \mathrm{~cm}$. $x 58 \mathrm{~cm}$. was covered with green felt. Five columns were indicated by spacing the numbers one through five equidistant across the top of the board. The numbers were written with a felt tipped pen and measured $4 \mathrm{~cm}$. in height. Eleven felt circles measuring $3 \mathrm{~cm}$. in diameter were aligned vertically in each column. Each circle was numbered from zero to ten and 
the numbered circles were distributed in each column in a random fashion.

Distractor. One copy of U. S. News and World Report (5 April, 1976) and one copy of Time (19 April, 1976) were placed on a small table in the room. Distractors were provided so that the subjects would have an alternative activity during the free time period.

Post experimental questionnaire. Eight self-report items were constructed to provide alternative dependent measures. The questions were aimed largely at eliciting the thoughts and feelings of each subject with respect to his or her tape and reward condition. Each question is discussed in detail in the Results section, below.

Experimental room. Each phase of the experiment was conducted in a small room, approximately $5 \mathrm{~m} \mathrm{~m} 3 \mathrm{~m}$, located above the school stage; it was relatively quiet and secluded, ideal for the study. Recording the tapes. All tapes were prepared by the experimenter; a male assistant's voice was used for the voice tapes. Music tapes were recorded directly from a high quality amplifier. Reward conditions required separate tapes because different reward instructions were contained on each tape. Each voice tape was identical to the other two, with the exception of instructions. Such was the case for the music tapes as well. The voice tapes were several seconds longer overall than the music tapes because of longer pauses between segments on the former. The music tapes were 920 seconds in total length and this time became the standard. Thus, if a subject 1istened to the voice tape for the entire 15 minute free time session, the time was recorded as 920 seconds even though it was actually several seconds longer. 
Procedure

Overview. Each subject was randomly assigned to one of three reward conditions (self-reward, external reward, and a no reward control) and to either a high or low interest task condition (music or voice). Subjects were asked to listen to either the high or low interest tape recording for five 1 minute trials. Pilot testing of several specific music and voice selections resulted in the final choice of the song Family of Man (Three Dog Night, 1974) for the high interest activity, and a male voice reciting the numbers from 1 to 150 as the low interest activity. Each listening trial was followed by a reward period in which the student either self-rewarded, received a reward based on the self-reward behavior of a yoked counterpart, or received no reward. After the five listening and reward trials came the collection of the primary dependent measure. The experimenter indicated that he had to leave the room for several minutes, during which time the student could listen to the tape or look at some magazines. A hidden timer unobtrusively recorded the amount of time the tape recorder was turned on during this "free-time period."

Instructions to subjects. Each student was met at their classroom and escorted to and from the room by the experimenter. The child was seated in front of the reward board, tape recorder, and button. The following instructions were presented to each child: (a) Self-reward.

Let me explain what this is all about. We are going to spend about $1 / 2$ hour together. I would like you to listen to some tapes on which is recorded (some music; a man's voice). 
For the first part I'd like you to listen to the tape for 5 minutes. After each minute of listening to the (music; man's voice) you will have a chance to pay yourself some pennies (show pennies) for listening. You know, sometimes when people do things they get paid. We1l, this is you chance to pay yourseld for listening to the (music; man's voice). After you listen to the (music; man's voice) for 5 minutes and pay yourself 5 times you will have a 15 minute free time period where you can listen to the tape or look at some magazines. I'll tell you more about the free time period when the 5 minutes (music; man's voice) is over. After you are finished with everything I will give you the number of pennies you have paid yourself. Let me show you how to do this. First you listen to the (music; man's voice) for a minute (play demo tape). Then the instructions on the tape will tell you its time to pay yourself. You see, you take a circle off the board that tells how many pennies you think you should pay yourself for listening to the (music; man's voice) for 1 minute. After you take a circle for the number of pennies you have paid yourself, you press the button and listen again for another minute. Then you pay yourself again. After 5 minutes the instructions will tell you to pay yourself for the last time and raise your hand and wait. Then I'll come over and tell you what to do next. Do you understand? Are there any questions? (b) External reward.

Let me explain what this is all about. We are going to spend about $1 / 2$ hour together. I would like you to listen to some tapes 
on which is recorded (some music; a man's voice). For the first part I'd like you to listen to the tape for 5 minutes. After each minute of listening to the (music; man's voice) you will be paid some pennies (show pennies) for listening. You know, sometimes when people do things they get paid. We1l, this is your chance to get paid for listening to the (music; man's voice). After you listen to the (music; man's voice) for 5 minutes and get paid 5 times you will have a 15 minutes free time period where you can listen to the tape or look at some magazines. I'11 tell you more about the free time period when the 5 minutes of (music; man's voice) is over. After you are finished with everything I will give you the number of pennies you have been paid. Let me show you how to do this. First you listen to the (music; man's voice) for a minute (play demo tape). The instructions on the tape will tell you it's time to get paid. You see, you take a circle off the board that tells you how many pennies you have been paid for listening to the (music; man's voice) for 1 minute. Remember, you always take a circle above the line, because that's what I've decided to pay you. After you take a circle for the number of pennies you will get paid, you press the button and listen again for another minute. Then you get paid again. After 5 minutes the instructions will tell you to get paid for the last time and raise your hand and wait. Then I'll come over and tell you what to do next. Do you understand? Are there any questions? 


\section{(c) Contro1.}

Let me explain what this is a11 about. We are going to spend about $1 / 2$ hour together. I would like you to listen to some tapes on which is recorded (some music; a man's voice). For the first part I'd like you to listen to the tape for 5 minutes. After each minute of listening to the (music; man's voice) you will take a circle from the board that means you have listened to the (music; man's voice) for 1 minute, it helps you keep track. After you listen to the (music; man's voice) for 5 minutes and take 5 circles you will have a 15 minute free time period where you can listen to the tape or look at some magazines. I'11 tell you more about the free time period when the 5 minutes of (music; man's voice) is over. Let me show you how to do this. First you listen to the (music; man's voice) for a minute (play demo tape). Then the instructions on the tape will tell you its time to take a circle. After you take a circle you press the button and listen again for another minute. Then you take a circle again. After 5 minutes the instructions will tell you to take the last circle and raise your hand and wait. Then I'll come over and tell you what to do next. Do you understand? Are there any questions?

After it was clear that the subject understood the overall procedure, the appropriate Music or Voice tape was played to the boy or gir1. Reward instructions were interspersed on the tape between each 1 minute segment of Music or Voice, as follows: 


\section{(a) Self-reward.}

OK, that minute of the music is over. When I say go, take your hand off the button and take a circle from column (1-5) that tells how many pennies you think you should pay yourself for listening to the (music, voice) for that minute. After you take a circle, press the button and listen again for another minute. Go. [Or after Trial 5.] After you take a circle, raise your hand and wait.

(b) External reward.

OK, that minute of the music is over. When I say go, take your hand off the button and take a circle from column (1-5) that tells how many pennies you will get paid for listening to the (music, voice) for that minute. After you take a circle, press the button and listen again for another minute. Go. [Or after Trial 5.] After you take a circle, raise your hand and wait.

\section{(c) Control.}

OK, that minute of the (music, voice) is over. When I say Go, take your hand off the button and take a circle from column $(1-5)$. The circle means you have listened for one minute. After you take a circle, press the button and listen again for another minute [except after Trial 5].

After the subject began listening to the tape, the experimenter moved to a position about 2 meters to the left, and slightly behind, the child. Thus, the subject could not see the experimenter directly 
during the reward treatment procedure. In this position the experimenter could also unobtrusively turn on the timer at the beginning of the free time period.

Free time data collection period. After each subject had gone through five listening trials, the instructions on the tape told the child to raise their hand and wait. At this point the experimenter joined the child and, as he took the reward board down, said the following:

\footnotetext{
We11, I'm going to put this over here, since we won't need that any more. Listen, I have to leave the room for several minutes. I'd like you to have a free time period while I'm gone; but, I'd like you to begin the free time period by listening, however, as soon as you don't want to hear anymore, Stop. There are a couple of magazines over there you can flip through until I get back. Remember, you can stop any time you want.
}

Timing for the 15 minute period began when the experimenter left the room. A spiral staircase that led up to the room made an ideal place for the experimenter to wait for the 15 minutes. The subject could be heard, although not seen, enabling the experimenter to make sure that nothing untoward was occuring. The procedure worked very smoothly and the experimenter never needed to interrupt a subject. Post-experimental questionnaire. After the 15 minutes expired, the experimenter returned to the room where he usually found the child looking at a magazine. The experimenter indicated to the child that he would like to ask the boy or girl a few questions about their parti- 
cipation in the study. The experimenter and subject sat adjacent to each other and each question was read aloud to the child as he or she looked along. The child was then asked to circle the desired response. After completing the questionnaire the subject was thanked, paid the appropriate amount of money, and escorted back to the classroom. The experimenter then returned to the room to record the number of seconds the button was depressed during the free time period and, in the selfreward and control conditions, the numbers on the circles taken from each column. If a yoked external reward subject was to follow, the reward tokens were arranged at the top of each column; a strand of dark wool was placed under the first row of circles because external reward subjects were told that when the instructions on the tape said to "take a circle," they should always take the circles above the line. If a control or self-reward subject were to follow, the reward circles would be reshuffled in each column to avoid a possible "position effect." 


\section{Results}

\section{Time-on scores}

The nean number of seconds spent listening to either the music or voice (time-on) during the free time period is presented in Table 1.

\section{Insert Table 1 about here}

These data were subjected to Hartley's $F_{\max }$ test to check the assumption of homogeneity of variance. The resulting $F_{\max }(12,7)$ of 13.45 did not reach significance; homogeneity of variance was confirmed. A $2 \times 3 \times 2$ analysis of variance was performed on the time on data. The analysis contained two levels of the Interest factor (music and voice), three levels of the Reward factor (self-reward, external reward, and contro1), and two levels of the Sex factor. Of the resulting $\underline{F}$ ratios, only the Interest X Reward X Sex interaction reached significance, $\underline{F}$ $(2,84)=4.60, \mathrm{p}<.05$. Figure 1 presents the interaction as it occurs in the higher interest condition, and Figure 2 presents the lower interest data.

\section{Insert Figures 1 and 2 about here}

The significant three way interaction was interpreted statistically by means of a series of simple interaction tests and simple, simple effects tests. Reward X Sex examined at the Music condition was significant, $\underline{F}(2,84)=3.88, \mathrm{p}<.05$. The simple interaction test at the Voice condition did not reach significance, $\underline{F}(2,84)=$ 2.26, $\mathrm{p}<.1$. Simple, simple effects tests focused on the Music 
$\underline{\text { Table } 1}$

Mean and standard deviations for time-on listening scores

\begin{tabular}{|c|c|c|c|c|c|c|c|}
\hline & & \multicolumn{2}{|c|}{$\underline{\text { Self-reward }}$} & \multicolumn{2}{|c|}{$\begin{array}{l}\text { External } \\
\text { reward } \\
\end{array}$} & \multicolumn{2}{|c|}{ Control } \\
\hline & & male & female & male & female & male & female \\
\hline \multirow{2}{*}{ Music } & $\vec{X}$ & 465.6 & 324.4 & 415.5 & 650.1 & 568.6 & 298.4 \\
\hline & SD & 261.6 & 266.1 & 284.5 & 321.3 & 290.8 & 130.0 \\
\hline \multirow{2}{*}{ Voice } & $\overline{\mathrm{X}}$ & 337.9 & 405.5 & 446.8 & 332.6 & 197.1 & 362.0 \\
\hline & $\mathrm{SD}$ & 160.6 & 279.4 & 309.8 & 364.4 & 99.3 & 285.7 \\
\hline
\end{tabular}


figure.1

MEAN NUMBER OF SECONDS OF FREE-TIME LISTENING FOR THE MUSIC CONDITION.

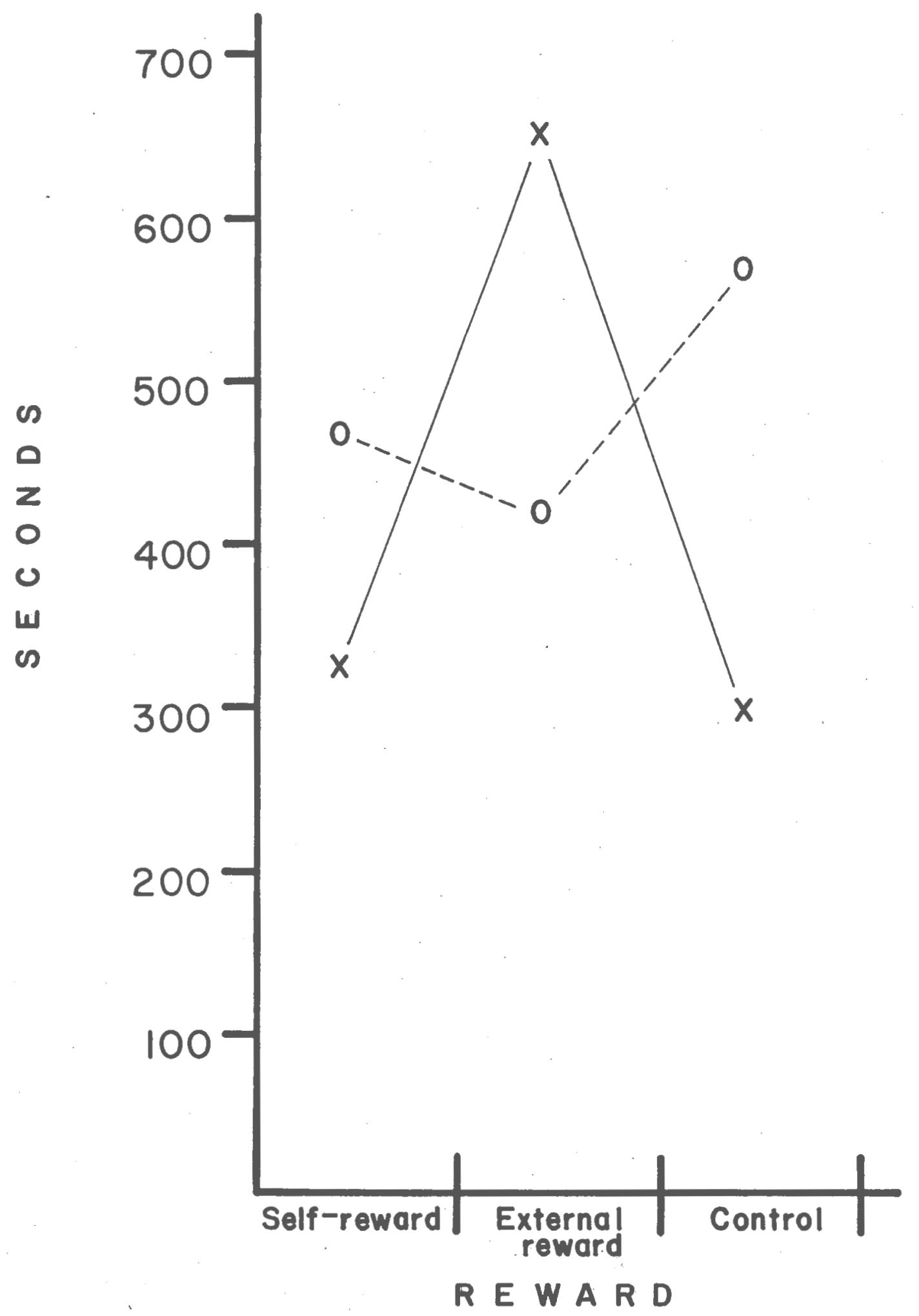

boys $=0$

girls $=x$ 
figure 2

MEAN NUMBER OF SECONDS OF FREE-TIME LISTENING FOR THE VOICE CONDITION.

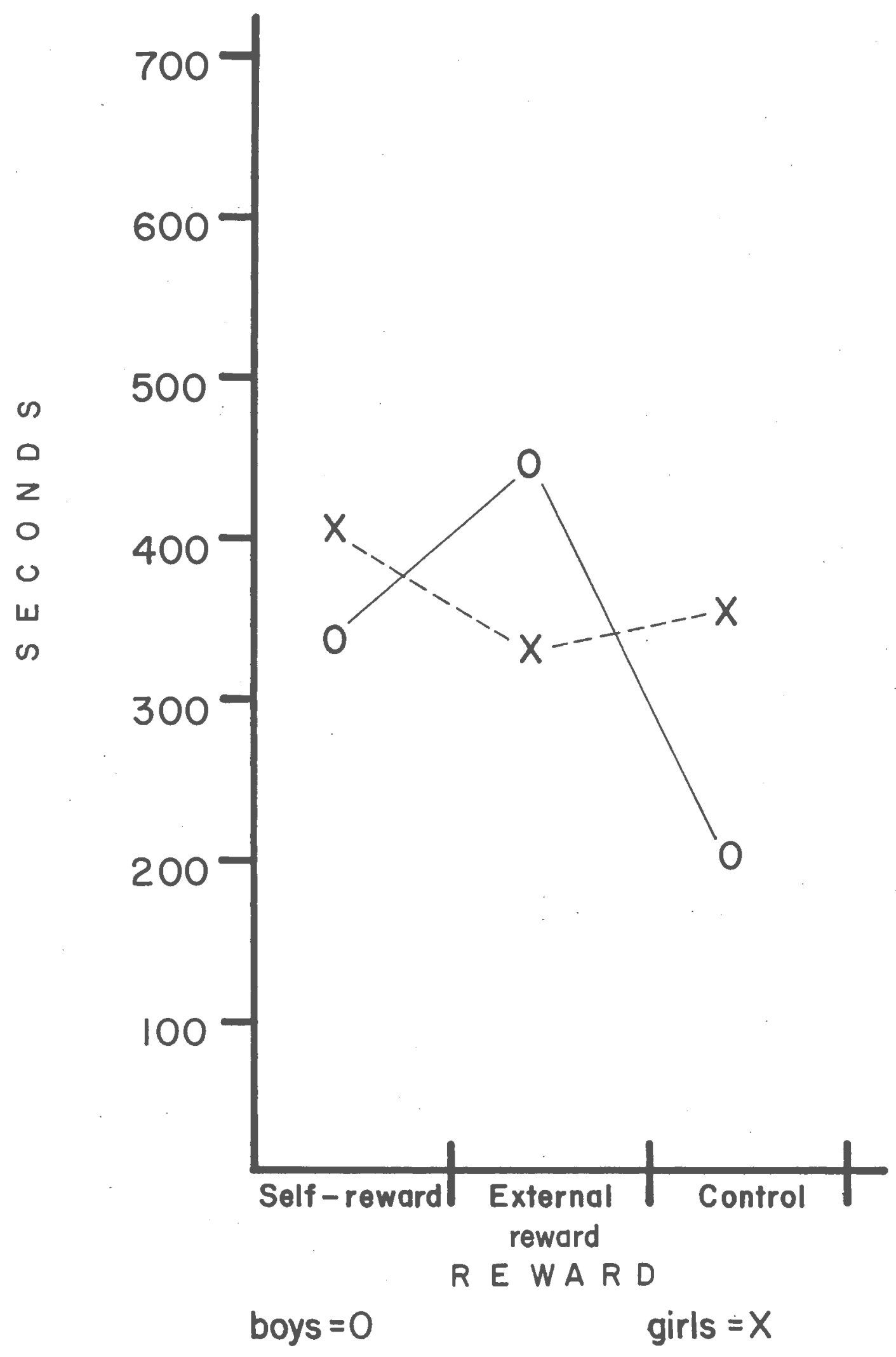


condition and found that the mean time on scores differed significantly for girls, $\underline{F}(2,84)=4.34, \mathrm{p}<.05$, but not for boys, $\underline{\mathrm{F}}(2,84)=.68$. Finally, a Neuman - Keuls test showed that the mean Iistening time for girls in the external reward condition was significantly greater than their mean listening time in either the self-reward or control condition. Hypothesis 1 predicted an interaction between external reward and task interest, such that free-time interest scores would be lower for the high interest task with respect to a control, and higher for a lower interest task compared to a control. Self-reward procedures were predicted to yield higher scores than a control in both interest conditions. The above analyses of time-on scores do not support any of the predictions derived from Hypothesis 1. However, a preliminary examination of the scores for the control group brings the true interest value of the music task sharply into question with respect to girls.

In otder to test for significant differences between the scores for the control groups in the two interest conditions, the three way interaction was examined at each of the three reward conditions. Simple interaction tests did not reach significance at either the selfreward or external reward conditions, $\underline{F}(1,84)=1.23$ and $3,42, p>.1$, respectively. However, a significant difference obtained at the control condition, $\underline{F}(1,84)=5.35, p<.05$. A simple, simple effects test of differences between the boy's scores in the control condition reached significance, $\underline{F}(1,84)=7.80, p<.05$. A test of the scores for girls in the control condition indicated no significant differences, $\underline{F}(1,84)=.22$. Thus, the assumption that the music task was of higher 
interest than the voice task was supported for boys but not for girls, for whom the voice scores in the control condition were nonsignificantly higher than the music scores.

\section{Self-reward scores}

The means and standard deviations for the number of pennies taken for each self-reward trial are presented in Table 2. An $F_{\text {max }}$ test con-

\section{Insert Table 2 about here}

firmed the assumption of homogeneity of variance, $\mathrm{F}_{\max }(20,7)=5.92$. Hypothesis 2 reasoned that self-reward magnitude is inversely related to task interest, and predicted that the self-reward scores for the higher interest task would be lower than the scores for the lower interest task. An analysis of variance performed on the self-reward scores yielded a significant main effect for the Trial factor, $\underline{F}(4,112)=4.37, P<.01$, and a significatn Trial $\mathrm{X}$ Sex interaction, $\underline{F}(4,112)=2.48, p<.05$. Care must be exercised in the interpretation of the main effect for Trials because of the significant interaction, which is illustrated in Figure 3. A series of simple effects tests probed for within and between sex differences in self-reward behavior across trials. Significant differences across trial were

found for males, $\underline{F}(4,112)=2.60, p<.05$, and for females, $\underline{F}(4,112)=$ 4.26, p <.01. A Neuman - Keuls test on the boy's self-reward scores found the Trial 4 differed significantly from Trials 1, 2, and 5. 


\section{$\underline{\text { Table } 2}$}

Means and standard deviations of self-reward for each trial

\begin{tabular}{|c|c|c|c|c|c|c|c|c|c|c|c|}
\hline & \multicolumn{5}{|c|}{ Male } & \multicolumn{5}{|c|}{ Female } \\
\hline & & 1 & 2 & 3 & 4 & 5 & 1 & 2 & 3 & 4 & 5 \\
\hline \multirow{2}{*}{ Music } & $\bar{X}$ & 6.25 & 6.38 & 6.38 & 7.88 & 6.65 & 5.88 & 6.38 & 6.50 & 5.63 & 8.38 \\
\hline & SD & 3.41 & 3.29 & 2.50 & 2.94 & 3.29 & 2.35 & 3.33 & 3.10 & 2.81 & 2.32 \\
\hline \multirow{2}{*}{ Voice } & $\overline{\mathrm{X}}$ & 5.25 & 6.63 & 7.50 & 7.88 & 6.25 & 4.38 & 6.63 & 7.75 & 7.00 & 7.25 \\
\hline & $\mathrm{SD}$ & 2.76 & 3.02 & 2.77 & 2.35 & 3.41 & 2.26 & 1.40 & 2.31 & 2.20 & 2.05 \\
\hline \multirow{2}{*}{ Tota1 } & $\overline{\mathrm{X}}$ & 5.75 & 6.50 & 6.94 & 7.88 & 6.44 & 5.13 & 6.50 & 7.13 & 6.31 & 7.81 \\
\hline & $\mathrm{SD}$ & 3.04 & 3.05 & 2.61 & 2.57 & 3.24 & 2.36 & 2.47 & 2.75 & 2.54 & 2.19 \\
\hline
\end{tabular}


MEANS OF SELF-REWARD SCORES FOR EACH SEX AT EACH TRIAL

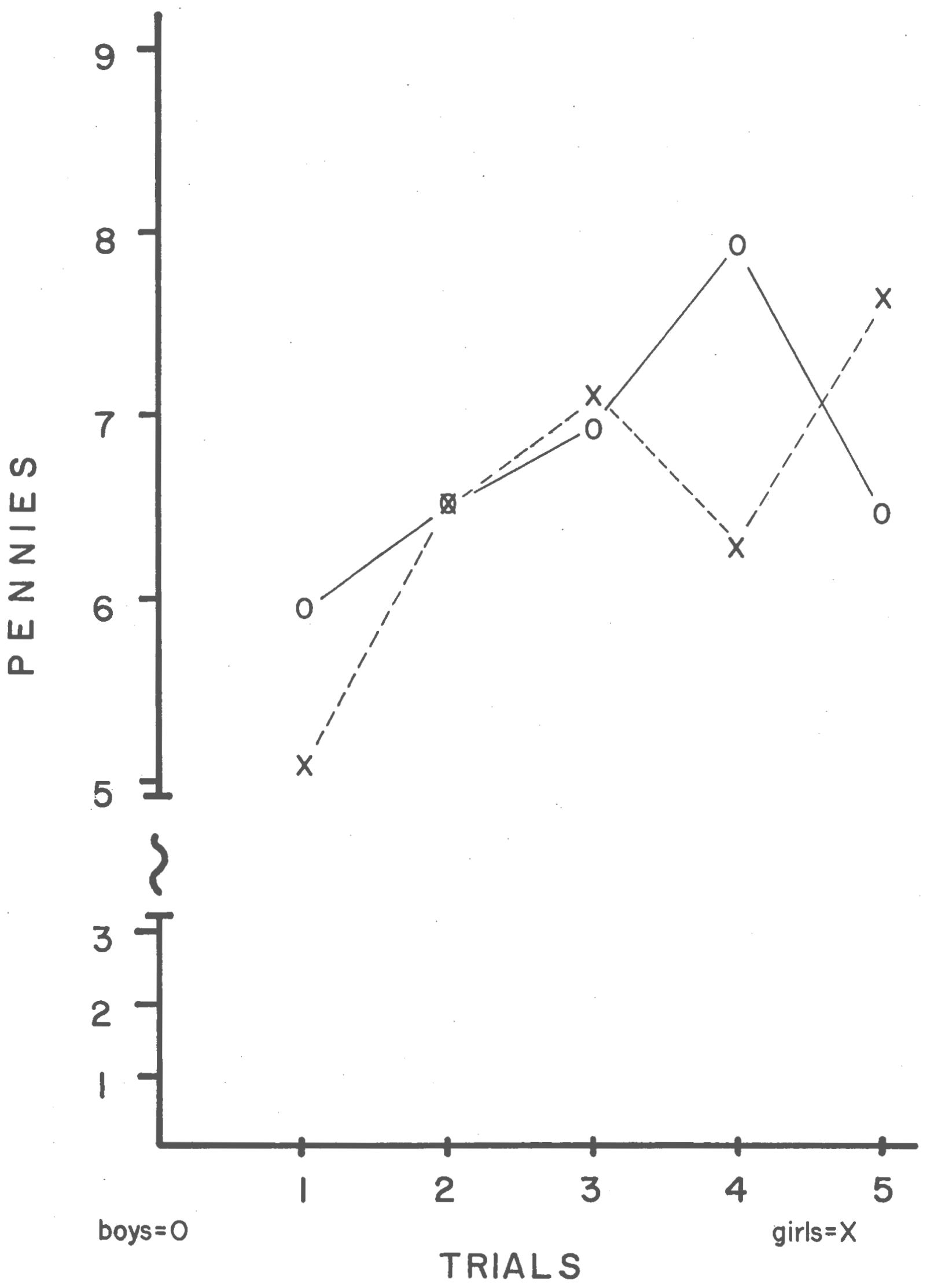


Similarly, it was found that for girls, all Trials differed significantly from Trial 1, and that Trial 5 differed from Trials 2 and 4. Simple effects tests found no between sex differences at Trial 1, $\underline{F}(1,140)=.41, \operatorname{Trial} 4, \underline{F}(1,140)=2.58, \mathrm{p}>.1$, or at Trial 5, $\underline{F}(1,140)=1.99, \mathrm{p}>.1$. In sum, Hypothesis 2 was not supported by the data. What does emerge, however, are several differences in the trial to trial behavior of each sex that may be indicative of underlying perceptions.

It is important to examine the trial to trial behavior of the children in the control group, in order to assess the reward perceptions of these subjects as compared to those in the self-reward group. It should be recalled that control subjects were asked to take a numbered circle for each listening trial, but were told that the circles simply served as one minute indicators. The means and standard deviations for the scores of the control subjects is presented in Table 3. An $\mathrm{F}_{\max }$ test performed on the data was not significant, $F_{\max }(20,7)=9.3$. An analysis of variance performed on the scores of the control group revealed no significant main effects or interactions.

Insert Table 3 about here

Reward magnitude and listening scores

The relationship between reward magnitude and the amount of time a subject listened to the tape during the free-time period was probed by means of a series of correlational analyses. Unfortunately, increased precision with respect to specific experimental conditions was met by progressively smaller sample sizes. In this instance, a sample 


\section{Table 3}

Means and standard deviations for each trial for numbered circles taken by controll group

\begin{tabular}{|c|c|c|c|c|c|c|c|c|c|c|c|}
\hline & & & & Male & & & & Femal & & & \\
\hline & & 1 & 2 & 3 & 4 & 5 & 1 & 2 & 3 & 4 & 5 \\
\hline & $\overline{\mathrm{X}}$ & 4.88 & 5.38 & 5.50 & 5.13 & 7.50 & 6.75 & 7.00 & 7.38 & 7.50 & 6.50 \\
\hline & SD & 3.31 & 3.36 & 3.62 & 2.53 & 1.69 & 4.02 & 3.16 & 2.38 & 2.50 & 2.94 \\
\hline & $\bar{X}$ & 5.63 & 6.88 & 7.88 & 6.63 & 5.38 & 4.88 & 6.88 & 4.25 & 5.63 & 5.88 \\
\hline & SD & 3.96 & 3.04 & 1.45 & 3.15 & 3.24 & 4.15 & 2.99 & 3.10 & 3.50 & 4.42 \\
\hline Total & $\bar{X}$ & 5.25 & 6.13 & 6.69 & 5.88 & 6.44 & 5.81 & 6.94 & 5.81 & 6.65 & 6.19 \\
\hline
\end{tabular}


size of 16 was the smallest used for correlation study. In addition, groups that differed significantly on the dependent measure of time-on scores were not combined because of a potential distortion of the correlations. Thus, the self-reward and external reward groups for females were not combined.

Analysis by sex across the three reward conditions is presented in Table 4, where $\underline{r}_{1}$ is the subject's total reward magnitude (except for control, where the score reflects the total of the numbers on the circles) and $\underline{r}_{2}$ is the time-on listening score. As can be seen, total reward and time-on scores are negatively related for females in the self-reward condition, $\underline{r}_{12}=-.47$, p. <.05. When the data for both

sexes are combined in each reward condition, the following nonsignificant correlations result: (a) for self-reward, $\underline{r}_{12}=-.02$, (b) for external reward, $\underline{r}_{12}=-.22$, and (c) for the control condition, $\underline{\mathrm{r}}_{12}=.22$.

Correlations by sex, combined across self and external reward, and also across interest conditions, are presented in Table 5. The Insert Table 5 about here

inverse relationship between the two variables for females is indicated by a significant correlation, $\underline{r}_{12}=-.40, \mathrm{p}<.05$, while the data for males reveals essentially no relationship between reward magnitude and time-on scores. 
Table 4

Correlations of time-on scores with total of numbered circles

\begin{tabular}{|c|c|c|c|}
\hline & Self-reward & External Reward & Control \\
\hline Females & $\begin{array}{c}-.47 * \\
(\mathrm{~N} 16)\end{array}$ & $\begin{array}{c}-.37 \\
(\mathrm{~N} \quad 16)\end{array}$ & $\begin{array}{c}.03 \\
(\mathrm{~N} \quad 16)\end{array}$ \\
\hline Males & $\left(\begin{array}{c}.36 \\
N \quad 16\end{array}\right)$ & $\begin{array}{c}-.09 \\
(\mathrm{~N} 16)\end{array}$ & $\begin{array}{c}.08 \\
(\mathrm{~N} 16)\end{array}$ \\
\hline
\end{tabular}


Table 5

Correlations of time-on scores and monetary reward scores for each sex

Males

.11

$(\mathrm{N}=32)$
Females

$-.40 *$

$(\mathrm{N}=32)$

$*_{p}<.05$ 


\section{Post-experimental questionnaire}

First the results of analyses of between group differences will be presented for each question, followed by correlations between responses on particular questions and the time-on listening scores. It should be emphasized that the following analyses are supplementary. The data lack precision compared to the behavioral measures reported above. They are, nevertheless, suggestive of meaningfuil relationships. Question 1. Children were asked, "How do you like the tape?" The structured response was "I think the tape is: Very Good (1), Good (2), Fair (3), Bad (4), and Very Bad (5). The mean rating for the Music and Voice tape was 2.91 and 2.81, respectively. Analysis of variance revealed no significant main effects or interactions. Question 2. "What do you think this is all about? What am I trying to find out?" was put to the children in an effort to discern whether they had thoughts about the study that might have distorted their performance. The vast majority of subjects indicated no idea whatsoever regarding the purpose of the study, while those that did respond almost always indicated that they thought the study intended to find out what they liked and did not like.

Question 3. This question asked, "When you get paid for something you like to do, how much do you like to do it when you are not getting paid anymore?" The children were asked to respond, "I like to do it: Much More (1), More (2), Just the Same (3), Less (4), and Much Less (5). The original intent of this question, and Question 4, below, was to determine the extent to which the children, regardless of treatment condition, could verbalize about the effects of rewards 
on tasks differing in interest value. Table 6 presents the percentages of subjects responding in each category. Although the vast majority ( $72 \%$ ) felt that rewards made no difference, $19 \%$ expressed the

Insert Table 6 about here

belief that rewards increased the enjoyment of already enjoyable tasks, while $10 \%$ thought rewards yielded a decrease in enjoyment.

All the subjects in two cells chose the same response and because of the resultant absence of variability, and analysis of variance was not performed.

Question 4. Table 7 presents the percentage of responses in each category, from Much More (1) to Much Less (5), to the question, "When you get paid for something you do not like to do, how much do you like to do it when you are not getting paid anymore?" As can be seen, an absolute majority (57\%) rated unenjoyable tasks as less enjoyable after the cessation of reward, while $13 \%$ rated such tasks as more enjoyable, and $29 \%$ felt reward made no difference on subsequent enjoyment.

\section{Insert Table 7 about here}

A test of homogeneity of variance was not significant, $F_{\max }(12,7)$ $=6.03$. An analysis of variance found a significant main effect for the Interest factor, $\underline{F}(1,84)=5.18, \mathrm{p}<.05$. Thus, children in the Music condition rated unenjoyable tasks as somewhat more enjoyable, after reward cessation $(\overline{\mathrm{X}}=3.4)$ than children in the Voice condition $(\bar{X}=3.96)$. 
Table 6

Percent of students responding in each category
to Question 3 $\%$

(N)

Much more 7

( 7)

More

12

Just the same

72

(69)

Less

10

Much less

0

(0)

Table 7

Percent of students responding in each category to Question 4

$\% \quad(N)$

Much more

3

(3)

More

10

(10)

Just the same

29

(28)

Less

30

(29)

Much less

27

(26) 
Question 5. The children were asked to complete the sentence, "Listening to the tape was" with the choices "all work (1), more work than play (2), about the same amount of work and play (3), more play than work (4), and, all play (5)." A test for homogeneity of variance was not significant, $F_{\max }(12,7)=3.48$. An analysis of variance did not find any significant main effects or interactions, although the Interest factor approached significance, $\underline{F}(1,84)=3.22, \mathrm{p}>.05$.

Question 6. Subjects were asked to respond Yes or No to the question "The tape you heard costs one dollar. If you had the money, would you biy the tape in a store?" Response frequencies are presented in Table 8. A chi square analysis of these data did not reach significance, $\mathrm{X}^{2}(6)=10.27, \mathrm{p}>.1$.

Insert Table 8 about here

Question 7. Children in the self-reward and external reward conditions were asked how they liked paying themselves (or, getting paid), and could respond from Very Good (1), to Bery Bad (5). A test for homogeneity of variance was nonsignificant, $F_{\max }(8,7)=5.04$. An analysis of variance resulted in a significant main effect for the Reward factor, $\underline{F}(1,56)=5.91, \mathrm{p}<.05$. The children in the external reward condition rated payment somewhat more favorable $(\overrightarrow{\mathrm{X}}=1.72)$ than did the children in the self-reward condition $(\overline{\mathrm{X}}=2.16)$, although the combined mean ratings for both groups indicated favorable sentiments about payment, regardless of reward condition. 
$\underline{\text { Table } 8}$

Number of Yes and No responses to Question 6

Self-reward External reward Control

\begin{tabular}{lcccc} 
Music & Yes & 9 & 9 & 9 \\
& No & 7 & 7 & 7 \\
\hline \multirow{2}{*}{ Voice } & Yes & 10 & 3 & 5 \\
& No & 6 & 13 & 11 \\
\hline
\end{tabular}


Question 8. Children in all three reward conditions were asked, "If you did this again for pay, would you rather have me decide how much you get paid for listening, or would you rather decide how much you get paid?" The response frequencies are presented in Table 9.

\section{Insert Table 9 about here}

A chi-square analysis was significant, $x^{2}(6)=44.38, p<.001$. The data in Table 12 clearly indicate the children's preference that the experimenter decide the magnitude of reward. Only the Voice selfreward cell deviated from the pattern, with half the children favoring self-reward and half in favor of external reward. When questioned further, those children who preferred external reward decisions almost always indicated that the reason for the external choice was because "they might take too much."

Relationship of time-on scores to responses to Questions 3 and 4

A series of preliminary correlational analyses were performed and the data was collapsed across Sex and Interest factors when no differences were found. The correlations of time-on scores with responses to Questions 3 and 4 are presented in Table 10. The relationship be-

Insert Table 10 about here

tween time-on and responses to both questions yielded significant negative correlation coefficients for the external reward group only. Thus, the more a subject listened to the tape in the external reward condition, the more enjoyable they rated tasks that were rewarded. 
Table 9

Number of responses in each category for Question 8

Self-reward External reward Control

\begin{tabular}{|c|c|c|c|c|}
\hline \multirow{2}{*}{ Music } & $\begin{array}{l}\text { You } \\
\text { decide }\end{array}$ & 13 & 15 & 14 \\
\hline & $\begin{array}{l}\text { Decide } \\
\text { myself }\end{array}$ & 3 & 1 & 1 \\
\hline \multirow{2}{*}{ Voice } & $\begin{array}{c}\text { You } \\
\text { decide }\end{array}$ & 8 & 13 & 14 \\
\hline & $\begin{array}{l}\text { Decide } \\
\text { myself }\end{array}$ & 8 & 3 & 2 \\
\hline
\end{tabular}




\section{Tab1e 10}

Correlations among time-on scores and responses to Questions $3 \& 4$

$\begin{array}{lcc}\text { Self-reward } & \text { External reward } & \text { Control } \\ \mathrm{r}_{12}=.29 & \mathrm{r}_{12}=-.65 * * & \mathrm{r}_{12}=.34 * \\ \mathrm{r}_{13}=-.13 & \mathrm{r}_{13}=-.53 * * & \mathrm{r}_{13}=-.12 \\ \mathrm{r}_{23}=-.20 & \mathrm{r}_{23}=.46 * * & \mathrm{r}_{23}=-.12 \\ (\mathrm{~N} \mathrm{32)} & (\mathrm{N} \mathrm{32)} & (\mathrm{N} \mathrm{32)} \\ & & \\ * \mathrm{p}<.05 & & \\ * * \mathrm{p}<.01 & & \end{array}$




\section{Discussion}

Tangible reward and task interest

The principle question investigated in this research is whether children's interest in a task is differentially affected by selfimposed and externally imposed rewards. An hypothesis was put forth which stressed the greater sense of personal causation associated with self-reward, and it was predicted that self-reward procedures would increase subsequent task interest with respect to a control group. It was further hypothesized that externally imposed reward would interact with task interest such that monetary rewards would effect an increase in interest for low interest tasks, and a decrease in interest for activities of higher interest initially. Neither of the hypotheses received support. The only generalization effect of rewards that obtained in this study was in the direction predicted by traditional reinforcement theory. That is, an increase in subsequent interest was observed for girls in the externally rewarded version of the high interest task. The results of the analyses of time-on listening behavior will be discussed for each reward condition. Self-reward. Self-reward, operationalized in this study as a subject's self-determined number of pennies (from a range of 0 to 10 for each trial), did not result in increased task interest during a free-time period. Apparently the greater degree of personal control inherent in the self-reward procedure did not yield a more favorable affective and cognitive task orientation; or, if such an orientation was produced it did not generalize to the free-time situation. 
The responses to Question 7 showed that children who had been externally rewarded rated payment significantly more favorably than children who self-rewarded. Further, the results of Question 8 indicated that children preferred an external reward rather than a selfreward procedure. Perhaps the requirement to make self-serving decisions regarding someone else's money sufficiently increased the children's anxiety so as to mitigate other effects of personal control.

External reward. A stimulus generalization effect appears to have been observed for girls who were rewarded externally for listening to music. That is, time-on behavior was greater for this group, compared to self-reward and control groups of girls, when tokens were no longer supplied. By design, the duration of the generalization period was only 15 minutes.

Token economy review articles (Kazdin \& Bootzin, 1972; 0'Leary \& Drabman, 1971) consider stimulus generalization to be a crucial effect of a successful token economy. However, these reviews conclude that generalization to situations where tokens are no longer supplied does. not "just happen." Rather, specific programmatic steps must be taken to ensure its occurrance. It is noteworthy, then, that such a generalization effect was observed in the present study, even though it is puzzling why the effect did not obtain in the girls' Voice condition as well. Equally puzzling is the failure of boys in the Voice condition to respond with increased interest in the Voice condition. Sex differences with respect to the intended manipulations may be partially responsible for these and other results. Such possibilities will be discussed in a later section. 
Children's verbal self-reports. Questions 3 and 4 (see Tables 6 and 7) attempted to elicit children's perceptions regarding the relationship of reward, and initial and subsequent task interest. Overall, the children subscribe to an interaction position that differs from the interaction hypotheses of the investigator. That is, boys and girls believed that interest in enjoyable tasks is not affected by reward, whereas interest in less enjoyable tasks is reduced if rewards are withdrawn. The results of the behavioral measure of time-on do not contradict the children's polled position.

The correlations presented in Table 10 suggest that children in the external reward condition who listened to the tape longer tended to rate tasks that were said to be rewarded as more favorable regardless of whether the task was described as enjoyable (Question 3) or unenjoyable (Question 4). Why these relationships are restricted to the external reward group is unclear. Perhaps the wording of the question "When you get paid ..." had more impact on children who had just been externally rewarded, whereas self-reward or control children may have interpreted their reward experience as "paying myself," or as not getting paid at all.

No reward control: An alternative perspective. The primary purpose of the control group was to provide a reference point which could be used to assess the relative effects of the reward treatment conditions. The control group was, in effect, regarded as a baseline measure. However, the no-reward group can also be considered in terms of the degree of personal control available to the subjects. Thus, if the three treatment conditions of this study are placed on internal- 
external control continuum, it can be argued that the no reward condition imposes the least external control upon a subject, followed next by the self-reward condition, and finally by the external reward condition. In other words, the no-reward subjects can be said to have the greatest degree of autonomy because they are not required to receive tangible rewards belonging to the experimenter; rewards are primarily covert and individual.

Figure 4 presents the mean time-on scores arranged in order of

Insert Figure 4 about here

the personal autonomy inherent in each condition. Comparing the high autonomy control to the progressively lower autonomy reward groups, it appears that where control group interest is low (Boys at Voice; Girls at Music) reward conditions allowing lesser degrees of personal autonomy are followed by an increase in interest. On the other hand, where control group interest is relatively high (Boys at Music) reward conditions allowing for less autonomy are followed by a decrease in interest. Finally, the activity that is moderately interesting for the control group (Girls at Voice) is only slightly affected by the two reward conditions.

The above analysis is based on results which are largely nonsignificant statistically and is presented only as a consideration in the design of future studies. Conceptualizing the control group as a treatment manipulated on a personal control dimension may add a theoretical richness to past and future studies. 
MEAN NUMBER OF SECONDS OF FREE-TIME

LISTENING FOR MUSIC AND VOICE

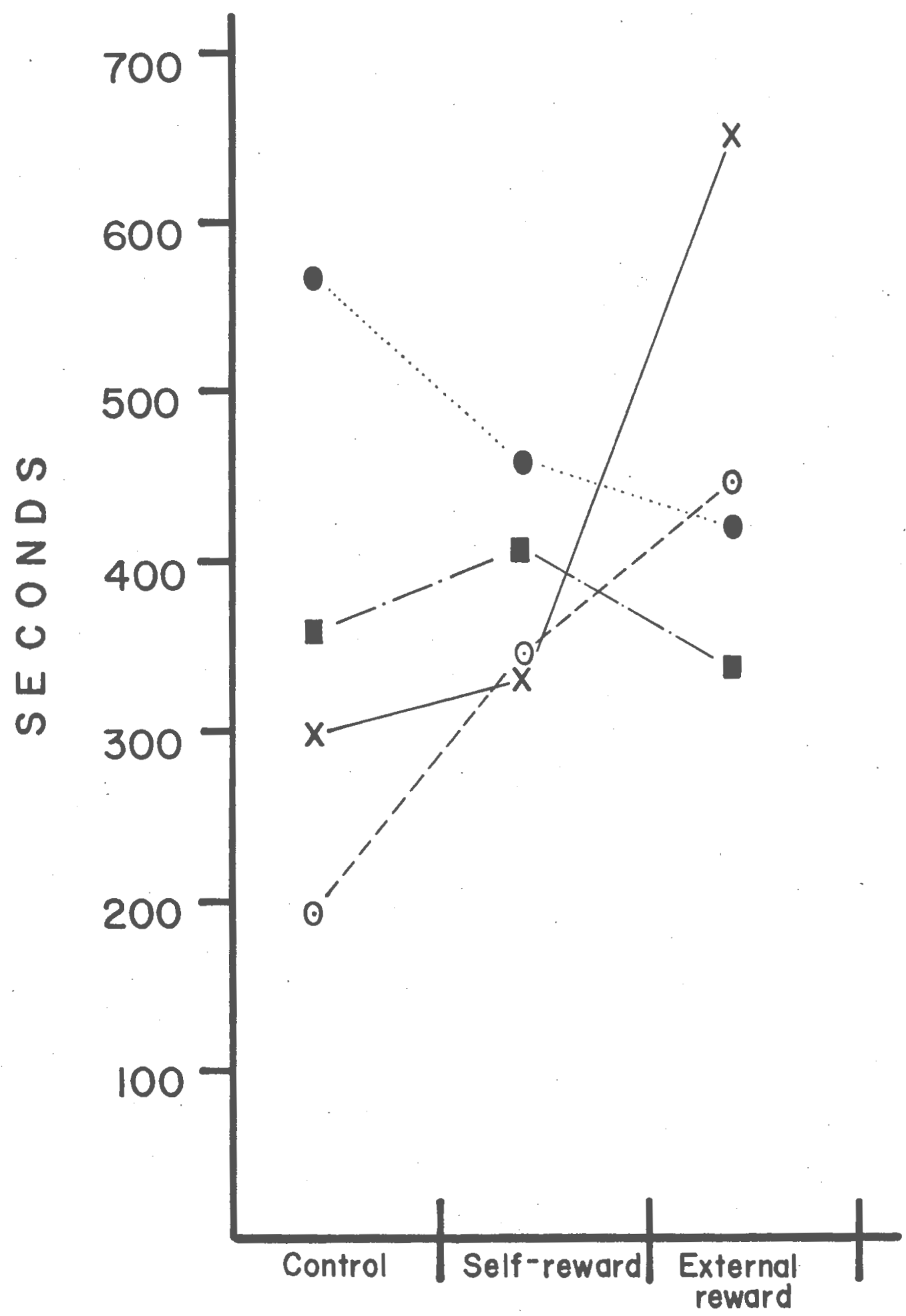

boys at voice $=0 \quad$ REWARD boys at music $=0$

girls at voice $=$ 믈 girls at music $=X$ 
Self-reward behavior

Contrary to the predictions derived from Hypothesis 2, children did not self-reward differentially across Interest conditions. Assuming that the task interest manipulation was perceived by the boys as intended, it is apparent that the task interest perceptions of the boys did not affect their self-reward behavior in the predicted direction. A speculative interpretation of the Sex X Trials interaction (see Figure 3) suggests an approach - avoidance conflict which is resolved differently by boys and girls. Children were faced with a situation in which they could maximize reward, i.e., nothing prevented a subject from taking a maximum of 10 pennies for each trial. However, results from probes to responses on Question 8 suggest that reward maximization involved social and psychological costs to the children. To take too many pennies would indicate to the experimenter (and to themselves as well) that they were greedy, that they lacked the selfcontrol prescribed by middle class culture. On the other hand, to take too few pennies would be to miss the rare opportunity to take freely of someone else's money. In short, self-assertion ran the risk of social approbation, while self-control occasioned social conformity at the risk of material loss. Trial 5 appears to be a decision point. Faced with the last trial, the children had to decide which kind of risk to take. The girls, as a group, took significantly more pennies on Trial 5 than on previous trials, while the boys took significantly less money on Trial 5. Apparently the girls decided to risk the negative opinion of the (male) experimenter, while the boys opted for a safe conformity. 
The significant effects for Trials raises the point initially posed by Reiss and Shushinsky (1975) regarding the tendency of several trials to reduce the frequency and strength of competing responses. It would be interesting to put the question to a direct test by comparing a one trial and a five trial procedure; such a manipulation remains for future research.

\section{Reward magnitude and listening scores}

Reward magnitude is usually directly related to level of performance (Marx, 1969). The results of correlations between a student's total reward (either self or externally administered) and the amount of time they listened to the tape during free-time observation do not conform to the traditional picture. There was no relationship between these two variables for boys. The girl's data, on the other hand, revealed a moderate inverse relationship between total reward and time-on scores (see Tables 4 and 5 ). The negative relationship manifested by females raises the possibility of important sex differences in response to reward. Most of the studies investigating the effects of rewards on interest do not include sex of subject as a critical variable. The present data suggest that more attention be paid to this variable.

The relationship of reward magnitude to interest is one that has received little attention in the studies examining the effects of reward on interest. Most such studies do not vary reward magnitude and thus cannot speak to this issue. Reward magnitude is a basic consideration of reinforcement procedures. Future research should be designed to enable precise manipulation of reward magnitude. 


\section{Effectiveness of intended manipulations}

The results of this study must be interpreted in relation to the validity of manipulations. It is not unreasonable to assume that boys and girls had different perceptions of the behavior unit in question, which includes the task, the reward, the experimenter, and the physical surroundings. An attempt to ferret out plausible explanations of results begins with the question of whether boys and girls experienced the tasks in the same way, and in the manner assumed by the experimenter.

An examination of the time-on scores for the control group (see

Table 1) suggests that, overall, boys may have perceived the Music condition as more interesting than the Voice condition, but that girls may not have experienced the interest manipulation as intended. Girls who received no tangible reward listened nonsignificantly longer to what was assumed by the experimenter to be a boring recording of a male voice singing.

It is curious that so many girls (and boys as we11) listened to the voice tape for such long periods in a situation is which they were alone in the room, free to listen to the tape, look at magazines or out the window, or to simply daydream. Whether the amount of time spent on the Voice tape was occasioned primarily by demand characteristics of the setting, or properties of the tape (possible the monotonic counting created a meditation-like situation) is unclear. Were the children hypothesis guessing and behaving accordingly? Most children reported no ideas about the purpose of the study. But what did they actually think? Or, perhaps the children interpreted the instructions asking them to listen to the tape for as long as they cared as an implicit 
request to listen for as long as they could endure it. It is equally plausible that each child had her or his own idiosyncratic reasons for their listening behavior. In this regard, it should be mentioned that thus far the discussion has focused on the behavior of groups, with the assumption that the behavior of the individuals constituting the groups is accurately reflected by the group means. However, and examination of the standard deviations in Table 1 indicates a wide range of individual variability with respect to on-task behavior in the free-time period. Attempts to measure a person's interest in an activity must, in future studies, design procedures to deal with a potentially wide range of preferences, even in regard to subject populations homogeneous with respect to age, sex, and geographic location. Perhaps a subject screening procedure would have helped ensure that only children with the appropriate level of interest for each task would be considered as potential subjects for the experiment.

Returning to the results for girls in the external reward Music condition, if it is assumed that the music actually possessed a low interest value for females, then the increased listening in the external condition is consonant with predictions. However, the failure for the girl's externally reward Voice Scores to Increase significantly is still unexplained, as are the scores for boys in the Voice condition. The other primary manipulations of the study involved the reward conditions. First, is there any evidence that the three reward conditions were perceived as different from one another? Whereas a significant main effect and interaction were found for self-reward scores, the scores for the numbered circles taken by the control group (see 
Table 3) showed no significant differences across Trials. The behavior of the control group suggests that the numbered circles were perceived differently than the numbered circles (i.e., tokens) taken by the self-reward group.

The responses to Qeustion 8 provide indirect evidence that the subjects of the study recognized some differences with respect to whether one's reward magnitude is determined by the self or another. The results presented in Table 9 show the responses of all but one cell to be significantly in favor of external reward procedures in a hypothetical future study. However, responses in the self-reward cell in the Voice condition do not differ significantly from chance expectations. Perhaps having experienced self-reward for a low interest task was sufficient to build positive attitudes towards what is undoubtedly still an infrequent and unfamiliar school experience, i.e., the chance to reward oneself.

\section{Summary and conclusions}

The experiment reported above failed to find significant effects for self-reward procedures with respect to increased task interest, and failed to replicate the results of previous studies in regard to decreased task interest subsequent to reward. Additional experimental research, using more refined procedures than those described in this report, should be conducted to further investigate self-reward and external reward effects on task interest. Particular attention should be paid to basic subject and reward variales such as age, sex, and personality differences, as well as kind of reward, reward magnitude, and reinforcement schedules. Based on the difficulties of creating a 
laboratory situation substantially free of devastating demand characteristics, and one in which the dependent measures yield reliable and valid data, it is recommended that additional studies investigating reward effects on interest be undertaken in the natural environment as well. Naturalistic experimentation and observation seems ideally suited to a situation that is truly commonplace. Rewards, especially easily quantifiable tangible rewards such as money, are omnipresent in this society. Quite simply, people are continually rewarded for doing things in which they have an intrinsic interest. It is not infrequent to hear a member of a high status profession such as TV or movie personality comment that they sometimes feel guilty for getting paid so much to do something they love to do. Most of these people continue to perform the rewarded behavior, perhaps with as much vigor and enthusiasm as when they were hungry young apprentices. The point at which a labor of love becomes drudgery is occasioned by a multiplicity of factors, many of which revolve around the notion of personal control. The prison literature (e.g., Sobell, 1974) is replete with examples in an extreme situation. Advantage must be taken of these and other naturalistic manipulations. 


\section{References}

Bandura, A. Vicarious and self-reinforcement processes. In R. Glaser (Ed.), The nature of reinforcement. New York: Academic Press, 1971. Pp. 228-278.

Calder, B. J., \& Staw, B. M. Self-perception of intrinsic and extrinsic motivation. Journal of Personality and Social Psychology, $1975 \mathrm{a}, \underline{31}, 599-605$.

de Charms, R. Personal causation: The internal affective determinants of behavior. New York: Academic Press, 1968.

Deci, E. L. Effects of externally mediated reward on intrinsic motivation. Journal of Personality and Social Psychology, 1971, 18, 105-115.

Deci, E. L. Intrinsic motivation, extrinsic reinforcement, and inequity. Journal of Personality and Social Psychology, 1972, 22, 113-120.

Ford, J. D., \& Foster, S. L. Extrinsic incentives and token-based programs: A reevaluation. American Psychologist, 1976, 31, 87-90.

Goldfried, M., \& Merbaum, M. (Eds.) Behavior change through self control. New York: Holt, Rinehart, and Winston, 1973.

Kazdin, A. E., \& Bootzin, R. R. The token economy: An evaluative review. Journal of Applied Behavior Analysis, 1972, 5, 1-30.

Krasner, L. On the death of behavior modification: Some comments from a mourner. American Psychologist, 1976, 31, 387-388.

Lepper, M. R., \& Greene, D. Turning play into work: Effects of adult surveillance and extrinsic rewards on children's intrinsic motivation. Journal of Personality and Social Psychology, 1975, 31, 479-486.

Lepper, M. R., Greene, D., \& Nisbett, R. E. Undermining children's intrinsic interest with extrinsic rewards: A test of the overjustification hypothesis. Journal of Personality and Social Psychology, 1973, 28, 129-137.

Levine, F. M., \& Fasnacht, G. Token rewards may lead to token learning. American Psychologist, 1974, 29, 817-820.

Levine, F. M., \& Fasnacht, G. Levine and Fasnacht reply to Ford and Foster. American Psychologist, 1976, 31, 90-92. 
Lovitt, T. C., \& Curtiss, K. A. Academic response rate as a function of teacher and self-imposed contingencies. Journal of Applied Behavior Analysis, 1969, 2, 49-53.

Marx, M. H. Learning: Processes. New York: Macmillan, 1969.

Masters, J. C., \& Mokros, J. R. Self-reinforcement processes in children. In H. Reese (Ed.), Advances in child development and behavior (Vo1. 9). New York: Academic Press, 1974.

O'Leary, K. D., \& Drabman, R. Token reinforcement programs in the classroom: A review. Psychological Bulletin, 1971, 75, 379-398.

Reiss, S., \& Sushinsky, L. W. Overjustification, competing responses, and the acquisition of intrinsic interest. Journal of Personality and Social Psychology, 1975, 31, 1,116-1,125.

Ross, M. Salience of reward and intrinsic motivation. Journal of Personality and Social Psychology, 1975, 32, 245-254.

Seligman, M. E. P. Helplessness. San Francisco, W. H. Freeman, 1975.

Skinner, B. F. Science and human behavior. New York: Macmillan, 1953.

Sobe11, M. On doing time. New York: Scribner's, 1974.

Thoresen, C. E., \& Mahoney, M. J. Behavioral self control. New York: Holt, Rinehart, \& Winston, 1974.

Three Dog Night: Their greatest hits. New York: ABC Records, 1974 . 
Appendix A

Literature Review 


\section{Literature Review}

\section{Overview}

The review consists of two parts. In part one, the related theories and central concepts are discussed broadly, in an attempt to summarize their historical usage. These include the theoretical areas of intrinsic motivation, attribution, locus of causality and self-reinforcement. Part two contains a review of the studies done in recent years that have specifically investigated the effects of rewards on subsequent interest in an activity.

Intrinsic motivation. The concept of motivation is one of the core ideas of modern psychology. As a conceptual tool, motivation permits us to inquire about the causes of behavior. Indeed, the acceptance of the concept as a valid scientific tool assumes that there are causes and that they can be identified by means of the scientific method. The quest for the causes of behavior has inspired an enormous amount of theorizing and empirical investigation that deals with "chunks" of behavior of different sizes, i.e., atomistic, molecular, and molar. Attempts to explain all of human behavior by a single motivational theory (eg., Freud or Hull) have not lived up to expectations or to empirical testing. Frequent1y, the theoretical concepts have not been specified in ways that permit such testing. In recent years the drive reduction thrust of Freud and Hull has been complemented with the concept of drive induction as another source of motivation. Whereas drive reduction emphasizes tension decrease as a primary motive, behavior that is apparently aimed at increasing, rather than decreasing, tension has been addressed by such concepts as the 
curiosity drive (Berlyne, 1960) or the notion of intrinsic motivation (Harlow, 1950; Hunt, 1965) that has its theoretical roots in the writings of Montessori (1905) and Piaget (1936), among others.

The notion of intrinsic motivation implies a state in which behavior is motivated by stimuli present in the very act of behaving. Thus, an act is performed for its own sake (Murray, 1965) and not for any additional consequences. The extrinsic pole of the motivational continuum is characterized by rewards that go beyond the act of doing. Although the use of the intrinsic-extrinsic dimension in this paper implies the kind of broad dispositional state just described, the terms have been used to refer to more limited motivational states. Hunt (1965) for example, discusses intrinsic motivation in terms of the organism's information processing capabilities and need for stimulation. In this usage, a particular reason for performing the activity is inferred, i.e., a need for perceptual and cognitive stimulation. Whether a particular organism or species has a need for perceptual and cognitive stimulation of a certain kind at a particular stage of development is a largely unresolved problem. However, the term intrinsic motivation in its broad usage described above should not be confused with the term's more limited application, of, for example, the cognitive psychologists. In short, the reason why a particular act is performed for its own sake is a different question than simply whether an act is performed for its own sake. In summary, the concept of intrinsic motivation, as employed in this research, implies no particular class of perceptual, cognitive, affective, or motor 
involvement. An activity is intrinsically motivating if performed neither to avoid pain or to gain some additional pleasure not inherent in the activity itself.

The concept of intrinsic motivation, though conceptually sound from a common sense, personal experience point of view, becomes problematic when one attempts to operationalize the term. First, it can be argued that although a person appears to be engaging in an activity for intrinsic reasons (i.e., for its own sake) the individual may expect some additional extrinsic reward because the activity has been on a long enduring variable schedule. Expectation of reward must be guarded against and such protection is no simple matter. Prior conditioning remains a potential source of error. Second, the circumstances under which an activity was first performed do not determine whether it is intrinsically or extrinsically motivated. Woodworth (1918) noted that activities originally performed for some extrinsic reward may come to be intrinsically rewarding in their own right, thus anticipating Allport's (1937) notion of the functional autonomy of motives. Finally, it is important to recognize that the reward value inherent in a particular activity is relative to (a) the state of the organism, and (b) the range of alternative activities (Premack, 1971). Thus, for the food deprived organism, the opportunity to eat is of greater reward value than, for example, the opportunity to explore the environment. Such is not the case for the food satiated organism. Thus the reward value of an activity is in a constant state of flux, and attempts to identify the reward value of stimuli must avoid absolute judgments and be content to specify a rank ordering of preferences based on the immediate situation. 
Attribution theory. A cognitive attribution explanation is often used to account for the reported decrement in interest in an intrinsically interesting task when accompanied by an external reward. Therefore, a brief review of the attribution literature will be presented. Attribution theory seeks to describe and explain the phenomenon that people in everyday life situations attempt to understand and attribute motives to the behavior of others (Jones, Kanouse, Kelley, Nisbett, Valins, and Weiner, 1972). In the Western mode of thinking, the individual is constantly on the alert for cause and effect relationships. Michotte's work (1963) reveals that individuals tend to make fine discriminations in the physical world of objects with respect to whether event A caused event $B$. In the social realm, the notion that people attribute causal motives to others and that these attributions have important consequences for interpersonal functioning is grounded in the work of Heider (1958). To take a blatant example, if person A injures person B, it makes a great deal of difference for the course of the relationship whether $B$ perceives the injury as intentional or accidental. How B attributes A's motives will have more than a trivial influence on whether $B$ engages in forgiving or retaliatory behavior. A more subtle example of the attribution process is revealed in the following situation. Suppose a school child who has had a history of poor achievement and interpersonal difficulty suddenly behaves like the teacher's ideal - hard working, accepting of authority, a source of: no difficulty whatsoever. If the teacher learns that the child's parents have established a new code of discipline complete with rewards and punishments that are 
certain to be applied, the teacher is more likely to conclude that the child's new ways are not a result of any inner desire to improve (i.e, , a product of intrinsic motivation). Rather, the teacher is likely to attribute the reason for the behavior change to the influence of the contingent rewards and punishments. Further, this change in behavior may be devalued because of the extrinsic attribution. The child is, after all, not behaving appropriately because he wants to, but is doing so simply to gain reward and avoid punishment.

Another example of attribution involving the school situation comes from an experiment by Johnson, Feigenbaum, and Weibey (1964). Teachers were asked to rate two children, one (A) who consistently performed well, and another (B) who performed poorly for some teachers and improved greatly for others. Child B's initial poor performance was attributed by the teachers to internal factors, whereas his improvement was attributed to their own teaching. Thus, positive and negative outcomes tend to elicit different attributions. Mischel (1973) raises the additional possibility that, whereas simplistic trait attributions are often applied to the behavior of others, the influence of subtle and myriad situational factors is much more clearly recognized in regard to one's own behavior. The process of inferring one's own motivation is duscussed in the literature of self-attribution.

Self-attribution. Expanding the thinking on attribution initiated by Heider (1958), Bem (1967) has proposed the notion of selfattribution. Bem's theorizing applies the analytic framework of investigations interested in attribution of other's behavior (Jones 
\& Davis, 1965; Kelley, 1967). Thus, a central idea of Bem's approach is that we behave first and then attribute the cause of our own behavior as a result of our self-observations. Cognitive activity is said to often be in the form of post hoc appraisal of behavior, rather than a cause of behavior in the sense of premeditation.

Evidence supporting Bem's line of reasoning comes from a series of experiments focusing on overt behavior (Bandler, Madaras, \& Bem, 1968; Davison \& Valins, 1969; Kiesler, Nisbett, \& Zanna, 1969) as well as from the studies dealing with the observation of internal autonomic behavior (Schachter \& Singer, 1962; Nisbett \& Schachter, 1966; Ross, Rodin and Zimbardo, 1969).

Bem's notion of self-attribution was originally put forth as an alternative explanation to the findings of the cognitive dissonance experiments (Festinger, 1957). The self-attribution model appears to be a more direct and parsimonious explanation because it does not invoke the hypothetical mediational state known as dissonance. The essential difference between the two models will be illustrated with reference to the well known study of Festinger and Carlsmith (1959). Subjects were paid either $\$ 1$ or $\$ 20$ to tell another subject that a boring task was interesting. The investigators predicted that the group that was paid $\$ 1$ would come to view the task more favorably than those who received the greater amount. It was theorized that subjects who were paid only a small amount of money to lie would experience an uncomfortable state of dissonance that could be resolved by changing their cognitions toward the boring task in a more favorable direction. They hypothesized process 
is strikingly similar to the notion of rationalization put forth by the psychoanalytic school. Bem's analysis outlines how direct selfobservation could lead to a similar attitudinal change. Subjects who received $\$ 1$ and observed their own lie could "say to themselves" (have the cognition) that they must actually have enjoyed the task in order to have said what they did for such a small payment. The subjects who received $\$ 20$, on the other hand, observed themselves telling a lie for sufficient reward to justify their behavior. With the foregoing context as a beginning, the literature on self-attribution has expanded to include a variety of investigations that go well beyond the original dissonance experiments.

Perhaps the most well known of these studies is the Schachter and Singer (1962) experiment in which three groups of subjects were given injections of a stimulant (epinephrine). One group was told the substance was a stimulant, another that is was a depressant, and the third group was given no information. In subsequent interaction with a confederate, the deceived and no information groups responded more emotionally and in a manner similar to the behavior of the confederate. A self-attribution explanation was postulated. Subjects sought explanations for their physical sensations. In the absence of sufficient correct information, subjects reflected prevailing environmental conditions (i.e., the behavior of the confederate). Other studies of self-attribution have involved perception of fear (Valins and Ray, 1967), perception of pain (Nisbett \& Schachter, 1966), and self-attitudes in the course of drug therapy (Davison \& Valins, 1969). 
The point that the preceding studies are inteded to illustrate is the postulated lack of direct synchrony between thought and overt behavior. That is, there seem to be times that behavior flows without detailed premeditation. Subsequent self-observation and analysis suggest causes to the actor. Awareness of possible causes can itself be a cause for further change. Thus, the feedback loop made possible by awareness makes the process truly dynamic.

Put in perspective, the self-attribution model's axiom that behavior can precede thinking, is in sharp contrast to the Freudian model which views all behavior as a product of conscious or unconscious thought. It is in this break with tradition that Bem's work has made its greatest contribution. Psychological theory has now a significant option in its attempts to chart the often divergent course of thinking and acting. Bem's work has also provided the theoretical underpinning for the notion of overjustification.

Overjustification. Emerging out of the self-attribution literature is the overjustification hypothesis. Traditionally, cognitive dissonance experiments have asked subjects to perform behavior that is counter-attitudinal and, therefore, insufficiently justified. The focus of the overjustification paradigm requires subjects to perform behavior that is consonant with prevailing attitudes, with the expectation of rewards for so doing (e.g., Kiesler \& Sakumura, 1966). The behavior is both pleasant and rewarded, hence the term overjustification. Self-attribution theory predicts a weakening of prevailing attitudes in the face of reward: 


\begin{abstract}
A belief inference may result from observation of one's behavior if the behavior is perceived to have been elicited by one's intrinsic reaction to the stimulus toward which behavior was directed, but a belief inference will not result if the behavior is perceived to have been elicited by some aspect of the circumstances extrinsic to the stimulus" (Nisbett and Valins, 1972, p. 70).
\end{abstract}

In other words, if behavior towards a pleasant stimulus is affected by factors extrinsic to that stimulus, the behavior will be attributed to the extrinsic factors rather than to the stimulus. Thus, if a person is rewarded for stating an attitudinal position already firmly held, the person's self-observations may lead to attributions focusing on the external reward as a cause of the verbal behavior. U1timately, this kind of attribution process may weaken the strength of the attitude.

In several of the studies to be reviewed below that focus on the decrease in interest effect, an overjustification explanation is advanced. The notion that reward can affect attitudes has been extended to include overt behavior as well. A critique of this position begins by assuming that the cognitive overjustification explanation is true and by then examining the implications for human development. If people, as a general rule, cannot accept the situation of being rewarded for doing something pleasant, then the cognitive complexity and flexibility of the human species is brought into question. It is important to stress the near lawfulness of the prediction because the theory does not set boundaries for its own range of application. Yet, who among us would admit to being unable to handle the doublepositive situation without necessarily having to devalue the behavior in question? Clearly, the theory is grounded in assumptions of cogni- 
tive complexity that posit few de grees of freedom. A supporter of the overjustification notion might concede that the hypothesis was never intended to be a high level theoretical statement with universal applicability. It then remains for investigators to generate more refined theoretical statements that will begin to specify the circumstances under which the theory yields accurate predictions.

Perhaps a more devastating criticism of the overjustification position is that it totally ignores the affective domain. If one admits that performing a behavior significantly more or less than would normally occur involves a substantial affective component, then the omission becomes readily apparent, and glaring. Rather than talking about the explanation for the decrease in interest phenomenon (assuming, for the moment, the legitimacy of the finding) it seems more in line with a multiple causation model to discuss possible contributing factors. The cognitive dimension has been represented; locus of causality will introduce the affective domain as well.

\section{Locus of causality}

In the discussion of attribution of causality above, it was noted that causal motives of others and self can be attributed to either the actor or the environment. Research and theory from several sources indicates that in regard to self-attributions, it makes a very important difference if a person perceives his behavior as a product of primarily internal as opposed to environmental factors, and vice versa.

The area of locus of causality has been approached by both trait and situational perspectives. In the trait model, an important and stable part of a person's total personality is the degree to which one 
tends to attribute causality internally or externally. Rotter (1954) illustrates the trait point of view with his concept of the internal or external person. Attempts to operationalize the concept via Rotter's I-E scale, and others as well (e.g., Cranda11, Katkovsky, and Cranda11, 1965) have yielded results that have tempered initial optimism in regard to the amount of total variance accounted for by scores on the scale (Lefcourt, 1966). Failure to recognize the importance of situational factors may contribute to the often low prediction power of scores.

Richard de Charms (1968) indicates that his notion of the OriginPawn dimension. is meant to encompass both personality and situational dispositions with respect to the degree to which a person fells in control or controlled. At the philosophical level, de Charms believes that people can be aware of causality in the physical world only because they are aware of their own power of personal causation. People make things happen and they know it. Making things happen, being an Origin, is crucial for normal development and optimal functioning: "Man's primary motivational propensity is to be effective in producing changes in his environment. Man strives to be a causal agent, to be the primary locus of causation for, or the origin of his behavior; he strives for personal causation" (p. 269). Unfortunately, de Charms provides little evidence in support of the above proposition, nor does he discuss in detail the consequences of not perceiving oneself to be an Origin. In sum, the de Charms (1968) statement is more like a position paper than a tight logico-deductive theoretical statement. Seligman's (1975) recent book is both theoretically and empirically richer. In his attempt to find a common denominator for the 
various behaviors and states labled as depression, Seligman presents a wealth of animal and human data that indicates some of the largely dysfunctional effects of feeling helpless with respect to the environment (a Pawn, in de Charms' terminology). In general, the consequences of helplessness range from innocuous performance dysfunction on an experimental task to, in the more extreme but perhaps more real instances, dire depression and even death. So important seems to be the ability to control ones fate that even uncontrolled positive consequences have been shown to have negative effects on the organism (Seligman, 1975). Self-reinforcement, both positive and negative, may have vastly different consequences for the person as compared to reinforcement by another.

\section{Self-reinforcement}

Paradigms for investigating self reinforcement. First proposed by Skinner (1953), the concept of self-reinforcement has received considerable study (Bandura, 1971; Kanfer, 1970) and has come to be a central concept in the broader literature of self control (Thoresen \& Mahoney, 1974). In his partial review of the literature, Kanfer (1970) notes the partitioning of much of the experimentation in the area of self-reinforcement into three paradigms: the directed learning paradigm, the vicarious learning paradigm, and the temptation paradigm.

Using the directed learning format, self-rewarding and selfpunishing responses are studied as the dependent variables. In generai, subjects are asked to contingently self-reward using a variety of incentives such as chips, colored lights, or points. 
Frequently the subjects are required to self-reward contingent on their accuracy judgments, often on tasks that vary in degrees of ambiguity (Kanfer \& Duerfeldt, 1967; Kanfer \& Marston, 1963).

In the vicarious learning paradigm the emphasis has been on the effects of prior modeling experiences on the incidence of selfreinforcement (Bandura, Grusec, \& Menlove, 1967; Bandura \& Kupers, 1964). A typical task used in these experiments is a programmed bowling game. Subjects are required to self-reward based on their scores, which are controlled by the experimenter. Variables investigated include standards of the model in relation to success or failure experiences of the subject (Bandura \& Whalen, 1966) and level of model nurturance (Bandura, Grusec \& Menlove, 1967). The kinds of incentives used have generally been chips exchangeable for back up rewards and, occasionally, experimenter determined verbal self-evaluative statements (Bandura, 1971).

Finally, the temptation paradigm has used self-reward procedures to investigate cheating behavior. Thus, for example, Kanfer (1966) found that younger children and children who were ranked lower in the class by their teacher, took more "undeserved" self-rewards. In this experiment, children were required to guess a number from one to one hundred and to self-reward with points if they believed their guess to be correct. Since the probability of a correct guess is near zero, any self-reward was defined as undeserved.

Regarding stability of the self-reinforcement response, Marston (1964) report Day 1 - Day 2 correlations across five tasks as follows: nonsense syllables, .51; Benton Visual Retention Test, .52; clinical 
judgment task, .70, inkblots, .75; work association, .75. Kanfer, Duerfeldt, and LePage (1969) report a correlation of .68 between self-reinforcement frequency on two dissimilar tasks (time estimation and word association). Finally, Reschly (1973) reports correlations of self-reinforcement responses of 7 th grade students across three different tasks of $.47, .61$, and .70 . The above evidence suggests that self-reinforcement behavior has moderate stability across different tasks and within the same task at different testing times. However, an important finding is the relatively independent variation between self-rewarding and self-punishing responses (Kanfer \& Duerfeldt, 1968; Kanfer, Duerfeldt, \& LePage, 1969). It is, therefore, important to distinguish between self-reward and self-punishment as the two components of self-reinforcement.

The major findings of Kanfer, Banduara, and thier associates include the following generalizations (Bandura, 1971; Kanfer, 1970; Masters \& Makros, 1974): (a) Self-reinforcement has response maintenance capability. (b) Modeling has a profound influence on selfreward standards. (c) Self-reinforcement can be manipulated externally, much like any other response. (d) Individuals vary in base rates of self-reinforcement. (e) Self-reinforcement shows moderate situational stability. (f) Self-reward and self-criticism are not strongly related. (g) Task ambiguity is inversely related to rate of self-reinforcement. (h) Self-reinforcement rates are affected by developmental variables such as age, achievement, and intellectual factors. 
Personality correlates of self-reinforcement. Self-reinforcement has been conceived of as an important dimension of personality. Marston (1965) links self-reinforcement and the self concept in such a way that overt, but particularly covert verbal self-reinforcement, is said to mediate between the self concept and overt behavior. Empirical investigations in this area have yielded mixed results. Reschly and Mittman (1973) found a positive relationship between self-reward rate and scores on the Coopersmith Self Esteem Inventory. Marston (1964) found only partial relationships between self-reward scores and scores on the Bass Orientation Inventory. He found no relationship between self-reward and scores on the Rotter Internal - External Locus of Control scale. Bellack (1972) had similar results with the Rotter I-E scale. Oziel and Berwick (1974) failed to find a relationship between self-reward and the California Personality Inventory and Berger's personality scale. Finally, Switzky and Haywood (1974) found a direct relationship between intrinsically motivated subjects (as determined by the Haywood Choice Motivator scale and the Haywood Picture Motivation scale) and rates of self-reward.

In closing this overview of the area of self-reinforcement it is important to keep in mind that attempts to operationalize the concept in the laboratory have resulted in operations that are often far removed from the self-reinforcement process that is hypothesized to occur in the natural environment.

Naturally occurring self-reinforcement, like external reinforcement, can consist of either verbal or tangible consequences, or both. of course, self-reinforcement can be on a continuum from completely 
covert to clearly overt and public. Examples of overt, tangible selfreward would include a trip to a fine restaurant for dinner or any of the numerous other ways people can materially reward themselves. Covert verbal self-reward would involve congratulatory statements said to oneself. It would seem that the ease with which covert self-reward can be delivered would make this the more common form.

Laboratory self-reinforcement operations follow an experimenters necessarily uniform procedure from subject to subject. Thus, for the sake of experimental control and internal validity some degree of external validity is sacrificed. In the natural environment it would appear that certain behaviors would involve greater frequency and magnitude of self-reinforcement than others. Thus, the more meaningful a behavior is to a person the more likely that behavior would be followed by thorough self-evaluation. Covert self-evaluation should clearly possess reinforcing properties and it is possible that a distinction between self-evaluation and self-reinforcement is not theoretically justified. At any rate, it is important to note that the particular class of behaviors that tend to be followed by self-reinforcement will vary from person to person. Laboratory experiments probably distort self-reinforcement because they typically require each subject to self-reward (or punish) following the same task. Laboratory tasks are often trivial and meaningless to subjects, still further differentiating laboratory from naturally occurring self-reinforcement. Finally, the experimental subject is aware, while in the act of performing the task, that he will be required to self-reinforce upon task unit completion. It is likely that in its natural occurrance, self- 
reinforcement may be far less salient during task performance. A notable exception is the case in which the behavior is of such import to the person that the individual anticipates the nature of the selfevaluations to follow and in effect says "No, I cannot do that because I could not live with myself afterward."

In sum, all the laboratory attempts to date have, for the sake of control, operationalized the self-reinforcement process such that some of the person's naturally occurring autonomy and degrees of freedom with respect to the process are eliminated. Investigators have assumed that the self-reinforcement process can be distorted in such a way and still remain similar enough to the natural process to allow for generalization. The extent to which this assumption is true reflects the degree of confidence that can be put in the findings to date.

Task interest and externally administered rewards

According to Deci (1971), the general conclusion of many psychologists that extrinsic rewards tend to decrease intrinsic motivation has been premature since the question has not, until recently, received much empirical attention. In the past few years a variety of subject populations, operational definitions, dependent and independent concepts, experimental manipulations, and statistical analytic procedures have been employed to demonstrate that external rewards have a deleterious effect on intrinsic interest. As Deci et al (1975) comment: "Although any one of these five studies which support the hypothesis could be criticized, the important support comes not from any one study, but rather from the fact that this 
finding has been replicated several times" (p. 81). Judging from the published literature it would seem reasonable to conclude that the decreased interest effect is robust. However, because it is much less likely that studies that fail to find significant differences will be published, the pervasiveness of the phenomenon should not be overestimated. The following table presents an overview of the studies to date that have found evidence of a decrease in interest effect subsequent to reward. 


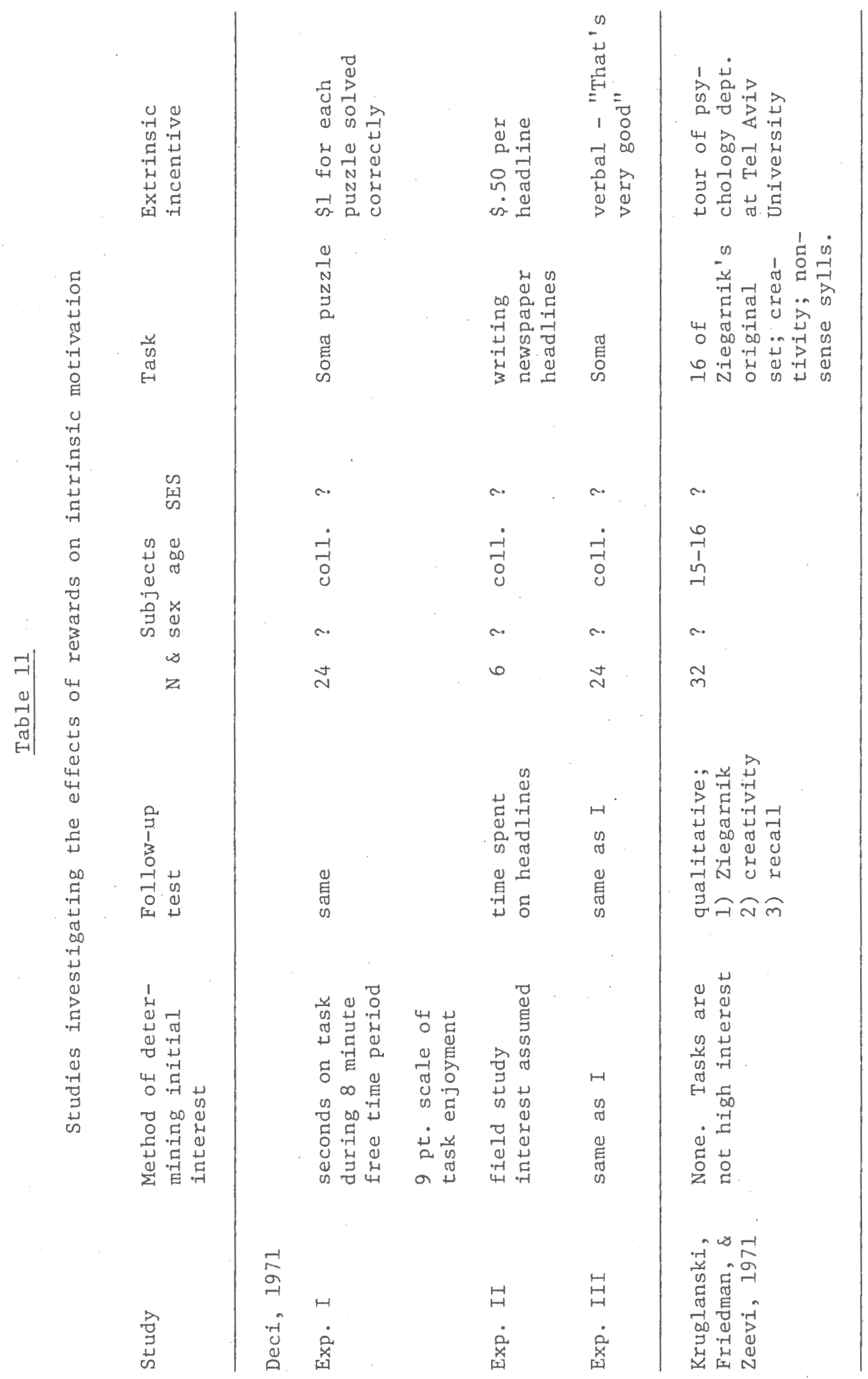




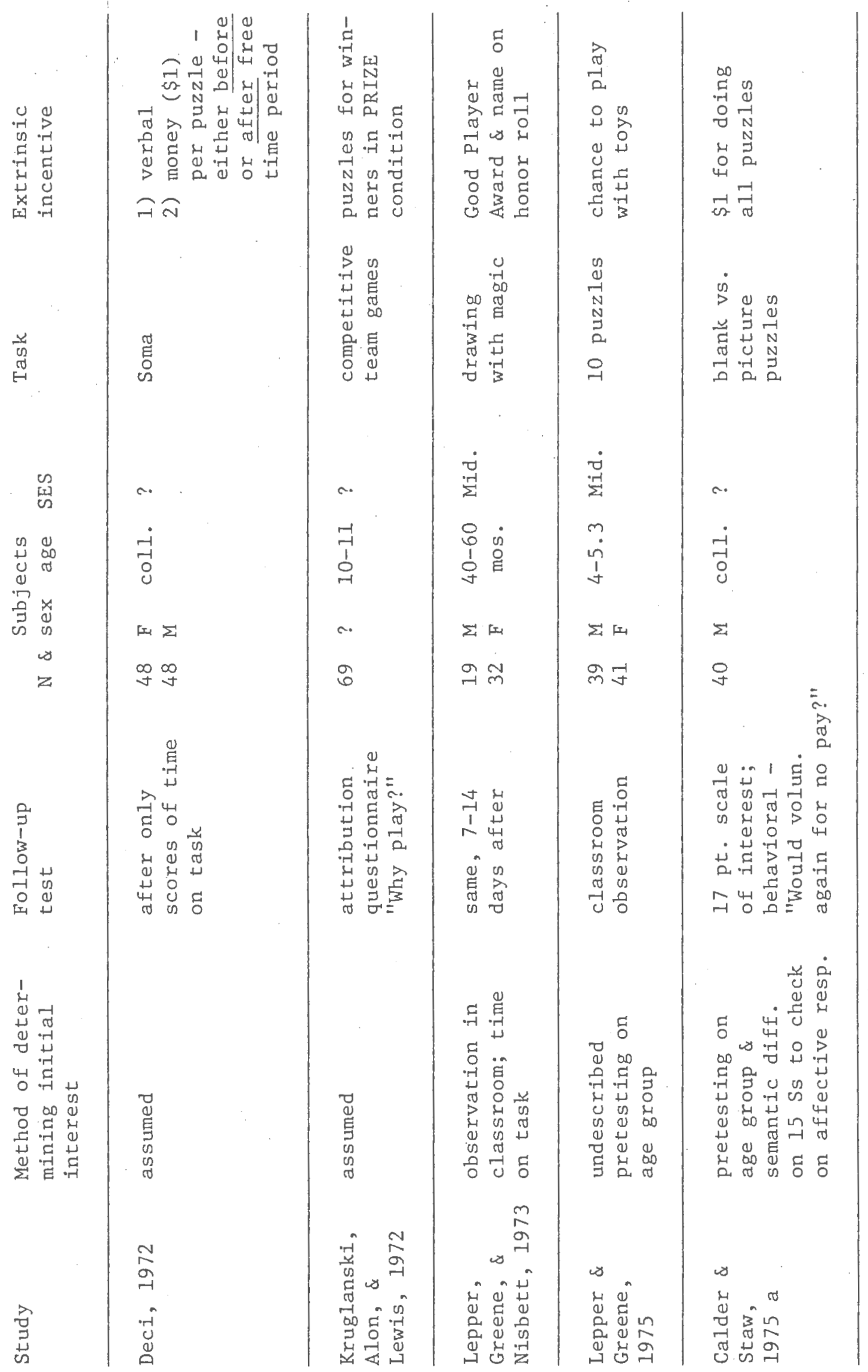




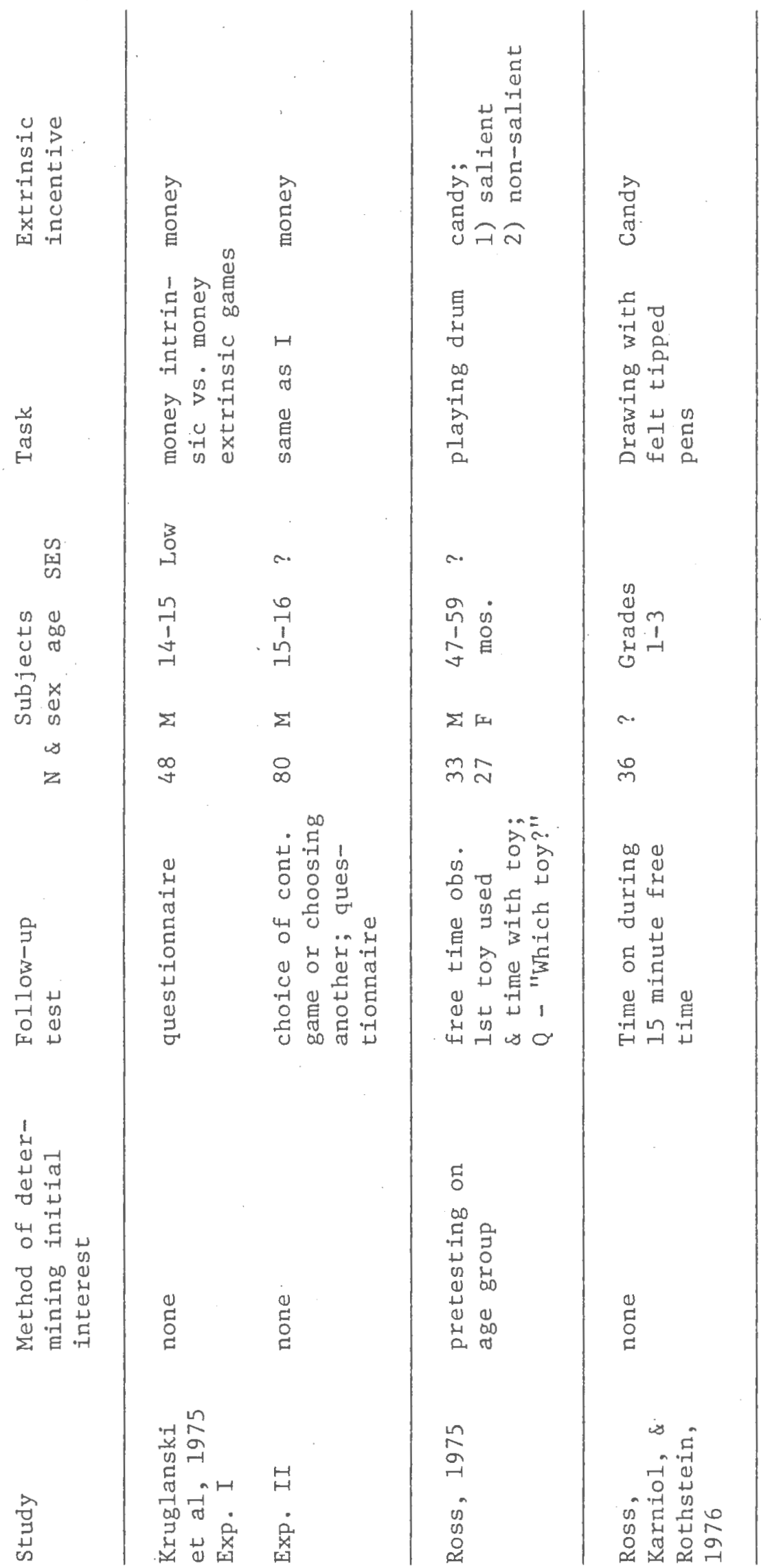


Each of the studies presented in the table reports a significant decrease in interest. Subject populations have ranged from college students (Deci, 1971, 1972; Calder \& Staw, 1975a) to nursery school children (Lepper et a1, 1973; Ross, 1975). Dependent measures have generally been observation of time spent with an activity during a free-time situation, but some studies have employed both behavioral and questionnaire measures (Calder \& Staw, 1975a; Ross, 1975). Observation sessions have either been built into the treatment free-time session (Deci, 1971, 1972; Ross, 1975) or have occurred several days after treatment (Lepper et al, 1973; Lepper \& Greene, 1975). Externa1 rewards have been predominantly tangible, with money the most frequently used.

Fina11y, the various tasks that have been employed consist primarily of psychomotor activities requiring varying degrees of skill. The question arises as to the generality of the findings along the receptive-expressive dimension. Does a decrease in interest effect obtain when a more passive high interest activity is employed? That is, does the amount of physical effort required by the task interact with reward and interest conditions? Cognitive evaluation theory makes no predictions regarding tasks differing across domains or modes. It may be that more sensitive measurement is required to detect interest decrements with passive tasks.

The Deci (1971) article reports on three experiments that examined the effects of rewards on performance of high interest tasks. Two experiments used the Soma puzzle task and rewards were either monetary or verbal. Subjects who received money spent less time 
with the puzzle during free time observation than did the control group. However, the difference reached only the .1 level of significance. On the other hand, subjects who received verbal reward in the form of praise worked longer with the Soma than a no-reward control group. Thus there is some evidence that verbal and monetary rewards may have substantially different effects. Unfortunately the sample size for all three experiments was smal1. The next Deci (1972) study is methodologically and conceptually more sophisticated. Ninety-six college students again worked with Soma; the group was partitioned into twelve treatment conditions. The factors manipulated were (a) type of reward, money or verbal, (b) timing of reward delivery, and (c) sex of subject. The summary table is reproduced below.

Mean number of seconds spent by subjects on puzzles in the 8 minute free choice period (Deci, 1972). free choice period (Deci, 1972).

$\begin{array}{cc}\text { No Verbal } & \text { Verbal } \\ \text { Reinforcement } & \text { Reinforcement }\end{array}$

\begin{tabular}{llllll}
\hline Condition & M & F & M & F \\
\hline Money after & 151.6 & 65.6 & 240.4 & 219.9 \\
\hline No money & 292.4 & 124.4 & 142.5 & 197.8 \\
\hline Money before & 346.0 & 248.0 & 384.4 & 329.9 \\
\hline
\end{tabular}

Several criticisms can be presented regarding analysis and interpretation of results. First, only the money/timing factor reached a customary level of significance (i.e., p<.005). The investigator, 
however, reports and attempts to interpret a main effect and interaction where $p>-1$. Such procedures are appropriate only if the researcher specifies in advance the accepted alpha level.

In regard to reward timing (the only significant factor), Deci employed inequity theory (Adams, 1963, 1965) and hypothesized that the group that received the money before the observation period would feel inequitably overpaid (guilty) and would therefore spend more time on the task than the reward-after or control groups. This hypothesis was supported. The group that received money before the free time period spent the most time with Soma during the observation time (594 seconds). The control group followed next (416.8 seconds); the group rewarded after free time showed the least interest in playing with Soma (217.2) seconds). Deci concludes his duscussion of results by noting that "large payments can lead to increased performance due to feelings of inequity, these payments will, however, be making the people dependent on the money, thereby decreasing their intrinsic motivation" (p. 120). Again, it should be stressed that Deci has only provided data to support the conclusion that overpayment can lead to performance increases. That performance increases are accompanied by a decrease in intrinsic motivation is a totally unsubstantiated claim. It seems illogical for an increase in free time contact behavior to be used to support an argument for a decrease in intrinsic motivation, particularly when the same dependent (i.e., contact behavior) measure is used as the operational definition of intrinsic motivation.

Kruglanski, Riter, Amitai, Margolin, Shabtai and Zaksh (1975) question the logic of Deci's (1971) formulation of intrinsic and extrinsic motivation. These authors interpret the Deci definition 
such that intrinsic motivation operates when a person sees the locus of causality in himself; extrinsic motivation results from the actor perceiving the cause for his actions in the environment. Kruglanski et al (1975) propose a content-consequence distinction. Specifically, intrinsic motivation is reflected by concern with the content of behavior and not with incidental consequences. Self-attributed concern with consequences defines extrinsic motivation. This formulation is, of course, in line with the definition presented above which indicated that intrinsic motivation is that which is done for its own sake. External rewards, such as money, can be differentially perceived on a novelty - tradition dimension according to these authors. They present data indicating that money tends to maintain high interest in games in which some financial rewards are traditionally present. In contrast, money introduced into games traditionally lacking such a feature tends to lower intrinsic motivation as measured by a questionnaire. The introduction of money where it traditionally does not belong does, of course, change the rules. Subject's preferences may have been adversely affected by any substantial change in rule structure. It may therefore be misleading to infer that game extrinsic money lowered preference (or intrinsic motivation). The study is nevertheless important because the notion of task-intrinsic versus task-extrinsic reward raises the issue of subjects prior learning history in terms of cultural and subcultural factors. Again, the relativity of reward is encountered.

The well known study by Lepper, Greene, and Nisbett (1973) claimed to be a test of the overjustification hypothesis. The subjects of the study were 55 nursery school children. After the col- 
lection of baseline interest data on a drawing task, some experimental subjects were told to expect. a Good Player Award for drawing. Proportion of time spent with the drawing material during an unobtrusive free time observation period was significantly less for the children in the expected reward condition. Subjects who received an unexpected reward did not show such a decrease. Similarly, drawings of subjects in the expected reward condition were rated as lower in quality than those of the unexpected or no reward groups.

Support for the overjustification hypothesis comes from the failure of the unexpected reward group to show a decrease in interest. The cognitive state of expectation appeared to make a difference. It is noteworthy that the results obtained with a nursery age population whose cognitive development might be thought to preclude the kind of self-attribution of causality required by overjustification theory. There is no direct evidence that the children did have the hypothesized cognitions, and overjustification is, at present, supported only by logical inference.

Al1 but one of the reveiwed studies dealt with reward effects on high interest tasks only. However, Calder and Staw (1975a) manipulated the same task on a high-low interest dimension. A poorly described pilot testing procedure determined that picture puzzles were of greater interest to the subjects than were the same puzzles with no picture or design. The results of this study revealed a significant interaction between task interest level and monetary reward. Task interest, as measured by a 17 point scale, decreased when followed by reward for the high interest picture puzzle, but 
increased for the low interest blank puzzle. The effects of reward on subsequent interest across tasks of different initial interest value requires further study.

As indicated earlier, the above studies have generated ongoing controversy regarding procedures and alternative interpretations of results. The potentially deleterious effects of token economies have been noted (Levine \& Fasnacht, 1974, 1976) and others have risen to the defense of such procedures (Ford \& Foster, 1976). There are critical articles from sympathetic investigators who seek to improve methods (Calder \& Staw, 1975b) as well as more vociferous comments by those who suggest that results are mere artifacts of procedures. Thus, Reiss and Suchinsky (1975) propose that the competing response hypothesis is a more parsimonious explanation of the Lepper et al (1973) findings. The former argue that the possible distracting effects of rewards presented in the treatment sessions could have evoked competing responses which interfered with performance during treatment and posttest conditions, eg., perceptual and cognitive distraction, excitement in anticipation of reward, or frustration from reward delay. They reason that a single reward trial is most likely to produce competing responses whereas "this effect [hurried or low quality performance] should be less likely to occur following repeated trials because subjects' initial excitement would be expected to subside" (p. 1,11). In short, loss of interest following reward is equated with the "decreased play effect" found by several other investigators (Barker, Dembo, \& Lewin, 1941; McCu11ers \& Martin, 1971; Miller \& Estes, 1961; Spence, 1971). In order to compare the overjustification hypothesis with the competing response notion they performed two 
experiments. In Experiment I, 32 first grade girls were divided into four groups: exposure-play, exposure-no play, no exposure-play, and no exposure-no play. The children were required to listen to a song for five minutes and reward groups were allowed to play with a doll for doing so, while the exposure groups were allowed to see the doll beforehand. Posttests 3-5 hours later recorded contact behavior with the target song. The results replicated the findings of Lepper et al (1973) such that children in the promised reward condition listened to the song significantly less than did those in the no promise-no reward condition. Further, merely pre-exposing children to the doll differentially had no effect. In Experiment II, nine Kindergarten children were assigned to one of three target song conditions. They earned tokens for listening to a target song for progressively longer periods (a multiple trial procedure). Forty-eight hours after training the children were posttested by their teachers. Contact behavior with the three tape recorders was recorded as the dependent measure. Results showed that the mean time for listening to the target song was significantly greater than the mean time spent listening to the most preferred non-target song. "Thus, the preference for the target song established during experimental training had transferred to the posttest situation. Clearly, this finding disconfirms the overjustification hypothesis' prediction of decreased interest in the target song, indicating instead an opposite effect" (Reiss \& Sushinsky, 1975, p. 1,122). These authors further question the utility of the intrinsic-extrinsic interest dimension and self-perception effects on overt behavior. "The behavior modification literature 
strongly suggests that perceived locus of control of self-behavior is a relatively unimportant variable for understanding the effects of reward procedures on overt behavior" (p. 1.123).

Lepper and Greene (1976) have written a cogent reply to Reiss and Suchinsky (1975) which includes the following points: (a) The theoretical distinction for the concepts fo intrinsic and extrinsic motivation have long divided psychologists along ideological lines and in their opinion this distinction is useful in understanding behavior under varying degrees of environmental control. (b) Intrinsically motivated behavior is seen in the operant tradition as simply behavior for which controlling stimuli have not yet been specified (Sidman, 1960). Comparing overjustification experiments to a variety of learning experiments where consideration of intrinsic motivation is irrelevant (e.g., Miller \& Estes, 1961; Spence, 1971) is inappropriate. (c) Using the token economy literature as a basis for evaluating the overjustification hypothesis is inaccurate "since it would appear that these studies rarely provide appropriate conditions for testing any hypothesis concerning decreases in subsequent intrinsic motivation" (p. 27). For example, token programs should be employed when attempting to modify behaviors of low frequency, whereas most studies examining the effects of reward on interest deal with high frequency behaviors (i.e., the operational definition of intrinsic interest often used). (d) They question why potentially distracting rewards should affect responses when the subjects are no longer in the presence of those rewards, i.e., in free play situations in which the subjects have never been rewarded in the past, and in which 
the subjects are assumed not to be expecting rewards. (e) It is pointed out that in Experiment II (Reiss \& Sushinsky, 1975) no control group was employed, such control necessary to examine the effects of experimental procedures such as increasing familiarity with the song, changes in liking for the nonreinforced alternatives, demand characteristics of the setting, etc. "Whether the provision of tangible reward would have increased, decreased, or have no effect on subsequent interest, relative to appropriate control conditions, is a question which these data are simply inadequate to answer. In addition, their failure to demonstrate any intrinsic motivation initially casts further doubt on the relevance of the study to our hypothesis" (p. 32). The studies reveiwed thus far have focused on differences among groups that have remained undifferentiated on personality dimensions. A recent study by Ross, Karniol, and Rothstein (1976) included an individual difference scale purporting to measure a child's propensity to delay gratification. Although a decrease in interest effect was evidenced by a group that received rewards, the delay of gratification hypothesis was not supported and the delay of gratification questionnaire was not associated with task interest. 
Appendix B

Pilot Studies 


\section{Pilot Studies}

\section{Task selection}

A pilot study was conducted in order to find a suitable task. A listening task was finally chosen because such an activity required minimal skill and could also be manipulated on an interest dimension by varying the content, which in this case included music as the higher interest listening activity, and a boring voice as the lower interest listening activity. The goal of the pilot study was to document whether listening to music was more attractive and interesting to a group of children similar to the subject pool for the main experiment, and also to select a particular music and voice selection. The major experiment also required a more or less neutral distractor to be present in the room along with the music and voice tasks. Magazines represent a common diversion in the culture, an activity that is performed while awaiting some more important event. Therefore, data was also sought on the kind of magazines that would be neither too interesting nor too dull for the age group of the study. Subjects came from a school system that closely resembled the subject pool of the main experiment. The students of two 5th grade classes participated, the group consisting of 23 boys and 24 girls.

One minute selections from each of three musical selections were recorded on a cassette tape. The selections, were in the jazz rock, bossa nova, and conventional rock styles. Similarly, three voice selections were also recorded, each a minute in duration. A male voice read a story about growing vegetables from a family magazine, spelled words, and recited the number from one to six multiplied by 
two ( the $2 \mathrm{x}$ table). Finally, three magazines were selected for presentation to the children, Family Circle, National Geographic, and U. S. News and World Reports.

A simple rating sheet was developed for distribution to the students. Children were asked to rank order tasks both within and between the categories. The format for all rankings was "The best is" and "The worst is". The middle choice is, of course, inferred.

Procedure. The investigator spent about half an hour in each of the two classrooms. The within category rankings occurred first. Ranking sheets were distributed t 4 the class and their use was explained. The three music selections were played and students rank ordered their preferences. The same procedure was followed for the voice selection. Magazines were ranked after being visually displayed for approximately one minute each. Children were then asked to complete the between category rankings.

Results. The percentages of children ranking each activity as either best or worst are summarized in Table 12 .

\section{Insert Table 12 about here}

In the between category rankings music and magazines were the preferred activities, while listening to voice was ranked worst by a large proportion of the children. In the music category, none of the selections received a great deal of support. Children appeared to prefer the sound of conventional rock, but more than a third thought this selection was the worst. The story about vegetables was a good deal more preferred than either spelling or the $2 \mathrm{x}$ table, and 
Table 12

Percent of students ranking tasds Best or Worst in pilot study

\begin{tabular}{|c|c|}
\hline Best & Worst \\
\hline$\% \quad(N)$ & $\% \quad(\mathrm{~N})$ \\
\hline
\end{tabular}

Between categories

$\begin{array}{lcccc}\text { Music } & 49 & (23) & 19 & (9) \\ \text { Voice } & 9 & (4) & 79 & (37) \\ \text { Magazines } & 43 & (20) & 2 & (1)\end{array}$

Within categories

Music

$\begin{array}{lllll}\text { Jazz rock } & 23 & (11) & 32 & \text { (15) } \\ \begin{array}{l}\text { Conventional } \\ \text { rock }\end{array} & 49 & (23) & 36 & \text { (17) } \\ \text { Bossa Nova } & 28 & (13) & 32 & \text { (15) }\end{array}$

Voice

$\begin{array}{lcccc}\text { Vegetables } & 62 & (29) & 32 & (14) \\ \text { Spelling } & 19 & (9) & 26 & (12) \\ 2 x \text { tàble } & 19 & (9) & 45 & (21)\end{array}$

Magazines

Family Circle

National

Geographic

U. S. News and

World Report
9 (4)

$75 \quad$ (35)

17 ( 8$)$
49

40

11 (5) 
the latter was ranked as worst most often. In the magazine category, National Geographic was the clear choice of most of the children, with Family Circle and U. S. News and World Reports each receiving a large proportion of worst rankings.

Discussion. Comparing the overall between category rankings it was clear that, because of the particular selections presented to the children, the music category was not overwhelmingly preferred over the magazines. On the other hand, the voice category's large proportion of worst rankings indicated that a selection of a specific voice could tentatively be made. Therefore, it was decided to select the voice segment of the $2 \mathrm{x}$ table as the low interest listening task; the need for additional data for the selection of the music selection was apparent. A second pilot study was conducted.

\section{Music and voice selection}

The same classes were used for the second study. Because of scheduling, absences, and other administrative factors, the group consisted of 18 females and 34 males.

A new music tape was prepared. Based on the experimenter's intuitive judgment, it was thought that the new tape would be much more popular with the children. The selection was "Joy to the World" by the well known rock group The Dog Night (1974). The $2 \mathrm{x}$ table was used for the voice selection, and only U. S. News and World Report was used in the magazine category (Family Circle seemed too sex-typed and oriented towards females). A revised questionnaire was prepared which contained a provision for rating, as well as ranking, the music and voice categories in order to get information on the strength of the preferences. 
The music, voice and magazine were presented to the children, after which they were asked to pick the best and worst categories and to rate the music and voice as Very Good, Good, Fair, Bad, or Very Bad. Table 13 shows the proportion of children selecting each category as either best or worst. The percentage of children rating music and voice from very good to very bad is presented in Table 14.

Insert Tables 13 and 14 about here

As predicted, the children almost unanimously preferred the new music selection, while slightly fewer children ranked the $2 \mathrm{x}$ table as worst. Within category ratings showed that $85 \%$ of the group rated music as either very good or good and $75 \%$ rated the voice selection as either bad or very bad.

Based on the above data it was decided to make Joy to the World and four similar tunes from the same album the tentative music selections and the $2 \mathrm{x}$ table the voice selection. Based on the opinions of U. S. News and World Report, the general category of newsmagazine was to be used for the distractor in the main study.

In summary, the two pilot studies enabled task choices to be made that were based on questionnaire data rather than on merely the intuitions of the experimenter. There is empirical support for the contention that the particular music selections are more interesting to the children of this age group than the particular voice selection. 
$\underline{T a b l e ~} 13$

Percent of students ranking each task category Best or Worst

Music
$\% \quad(N)$

94 (49)

Worst
Voice

$\% \quad(\mathrm{~N})$

$2(1)$

$77 \quad(40)$

19

(10) 
Table 14

Percent of students rating each task category from Very Good to Very Bad

\begin{tabular}{|c|c|c|c|c|c|c|c|c|c|c|}
\hline & \multirow{2}{*}{$\begin{array}{c}\text { Very } \\
\%\end{array}$} & \multirow{2}{*}{$\begin{array}{l}\text { Good } \\
(\mathrm{N})\end{array}$} & \multicolumn{2}{|c|}{ Good } & \multicolumn{2}{|c|}{ Fair } & \multicolumn{2}{|c|}{ Bad } & \multirow{2}{*}{\multicolumn{2}{|c|}{$\begin{array}{ll}\text { Very } & \text { Bad } \\
\% & (\mathrm{~N})\end{array}$}} \\
\hline & & & $\%$ & $(\mathrm{~N})$ & $\%$ & $(\mathrm{~N})$ & $\%$ & $(\mathrm{~N})$ & & \\
\hline Music & 50 & (26) & 35 & (18) & 12 & $(6)$ & 2 & (1) & 2 & ( 1 ) \\
\hline Voice & -- & $(0)$ & 8 & $(4)$ & 17 & (9) & 15 & ( 8$)$ & 60 & (31) \\
\hline
\end{tabular}




\section{Final task selection}

Two reward subjects and three control subjects were run through the experimental procedure to check on equipment functioning and to ensure that the music and voice tasks yielded free time listening scores that would meet the assumption of the homogeneity of variance. The data from these subjects were not used in subsequent analyses.

It became immediately apparent that both the listening tasks were too interesting, i.e., subjects tended to listen for the full 15 minute period or close to it. The music tape consisted of 5 one minute selections from five different songs. from the album by Three Dog Night. (1974). A new tape was prepared consisting of one minute segments from one songl only, Family of Man, from the same album. The $2 \mathrm{x}$ table was changed to what seemed to the experimenter to be an extremely uninteresting recording, the voice of a man counting from one to 150. Three pilot subjects were run through the new tasks and the free time listening decreased considerably, especially for what was desired to be the low interest voice condition. It was decided to use these tasks throughout the rest of the experiment. 
Appendix C

Analysis of variance summary tables 


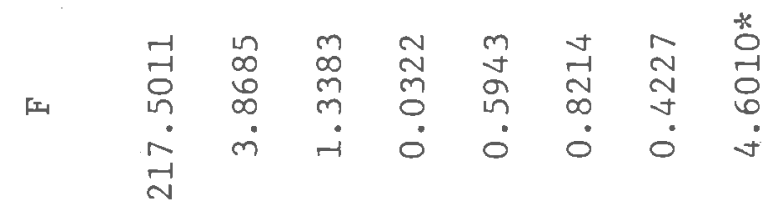

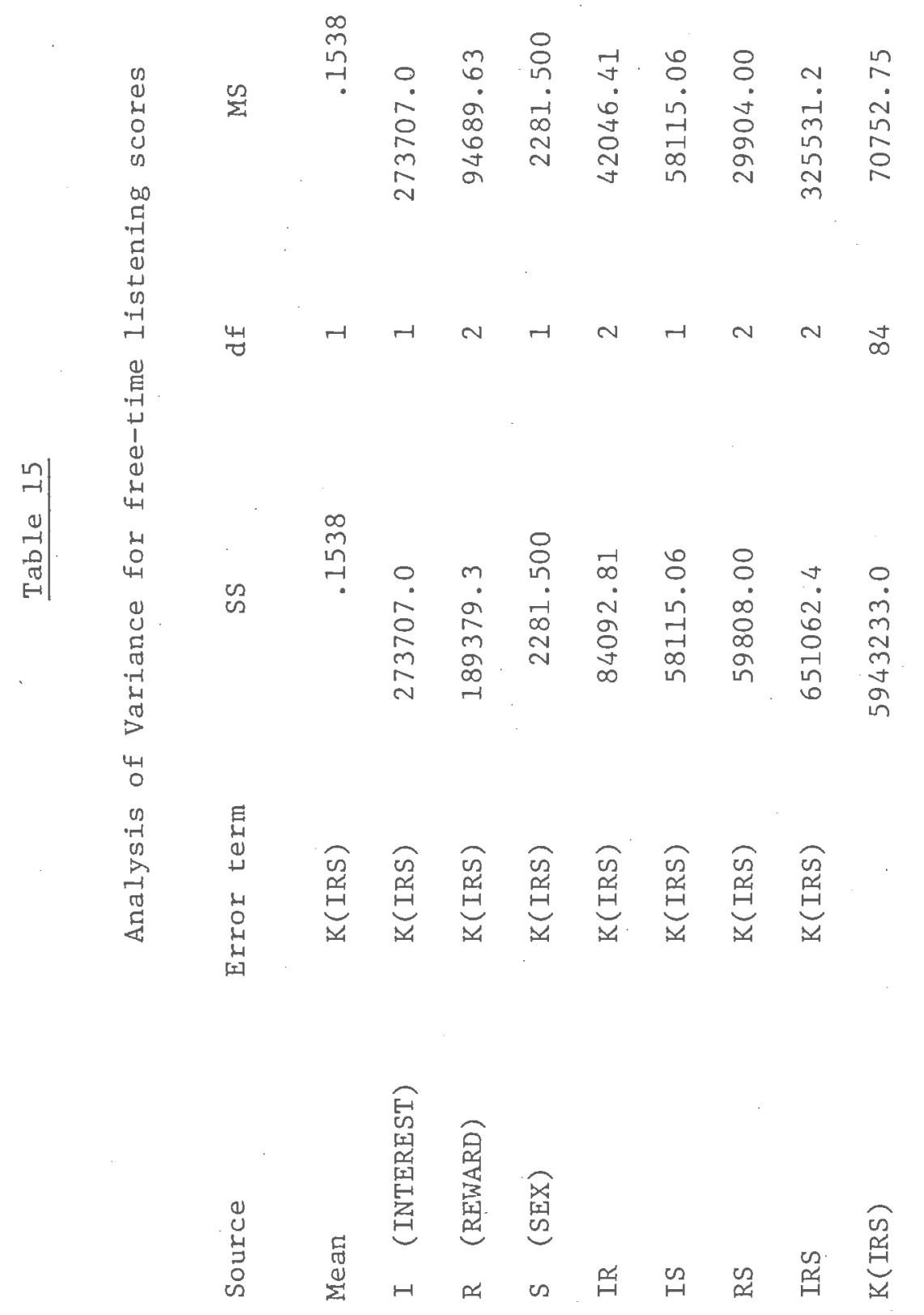




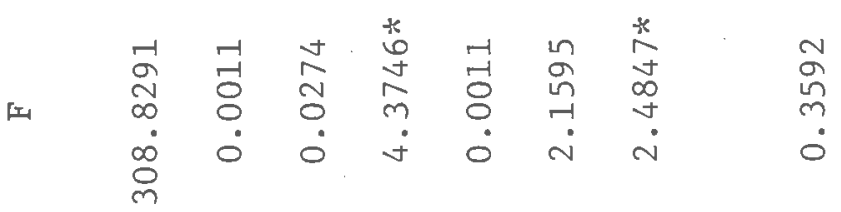

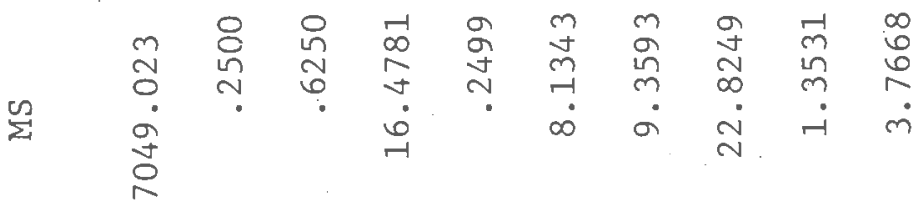

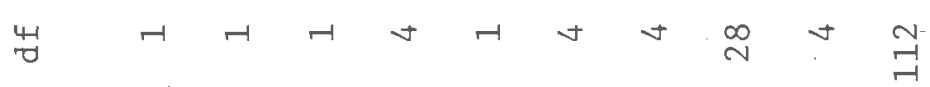

이 는

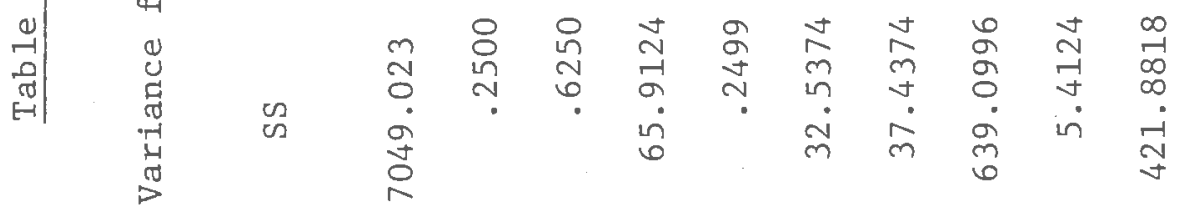

4

㝦

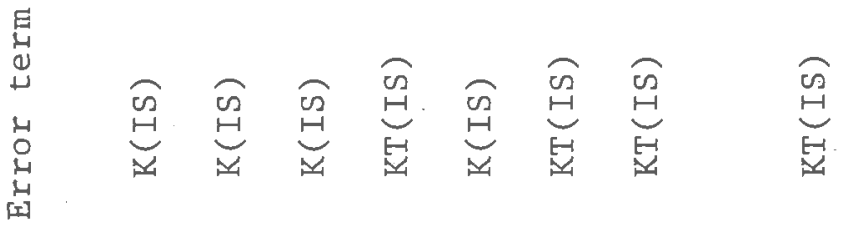

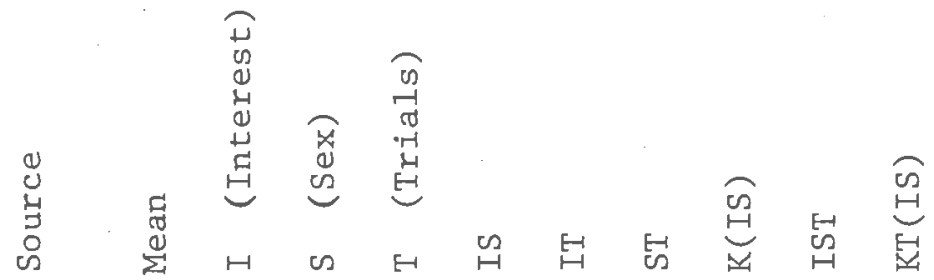




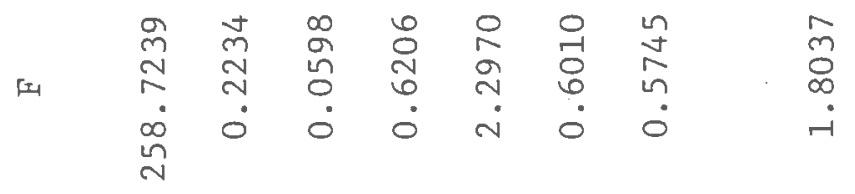

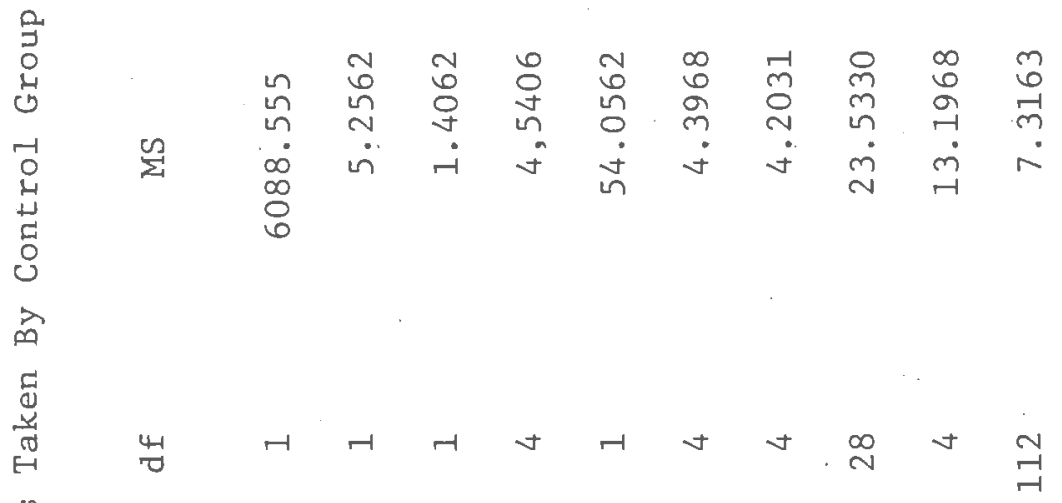

가 :

0
-1
0
0

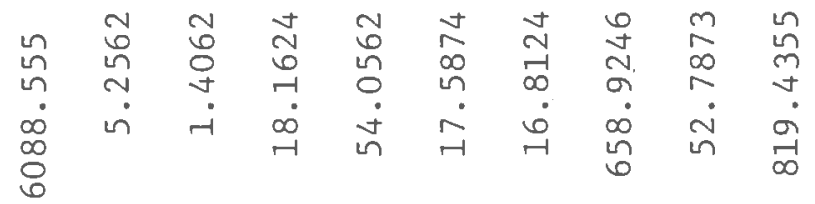

눈

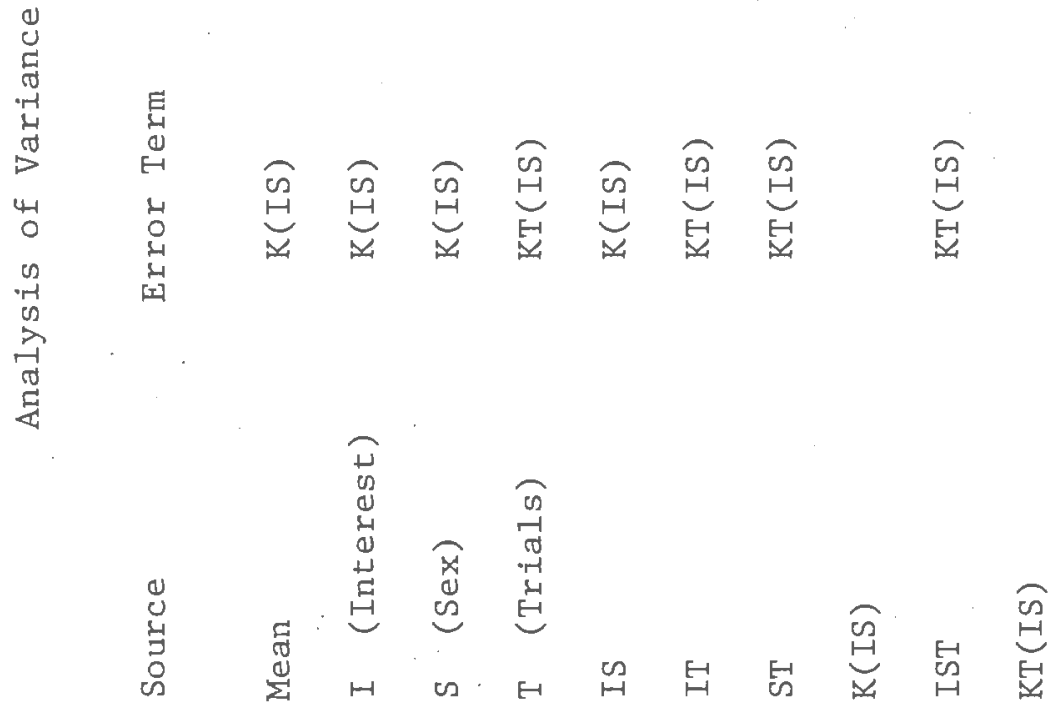




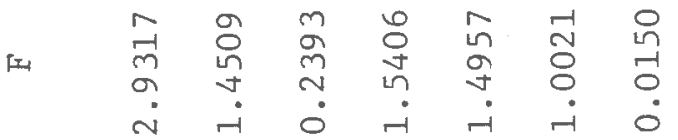

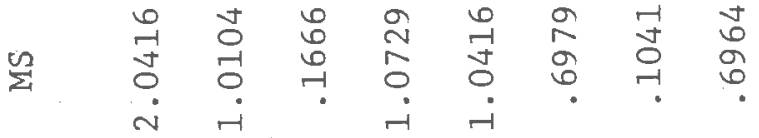

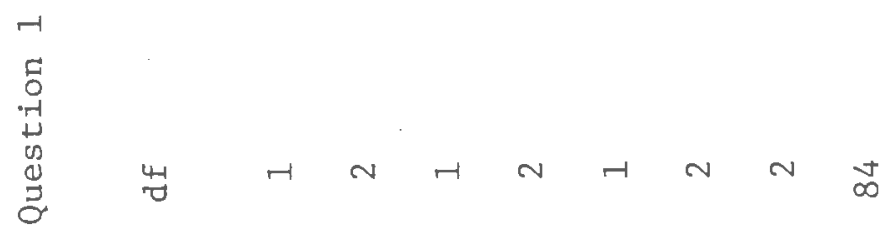

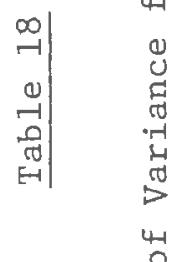

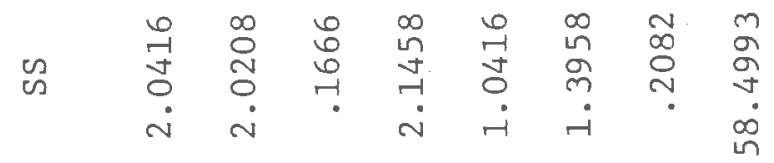

$\underset{\substack{n \\ \infty}}{\infty}$

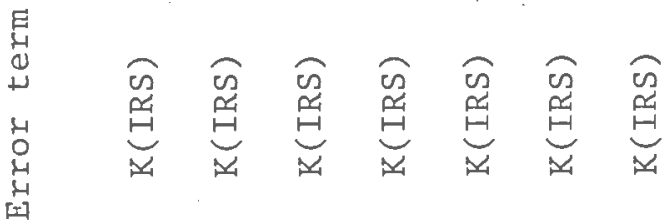

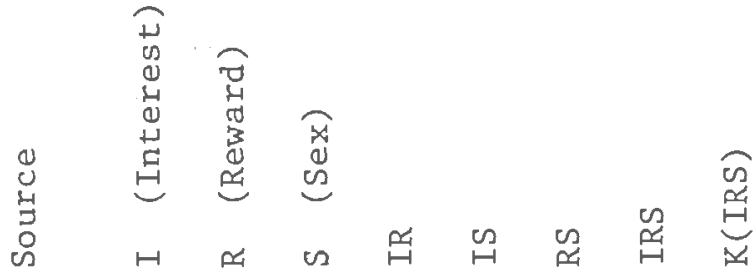




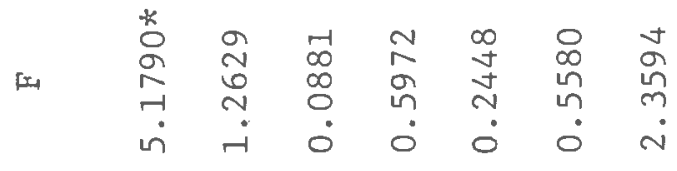

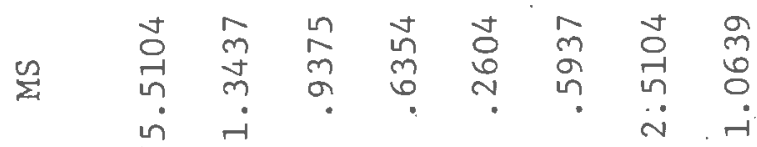

才

I

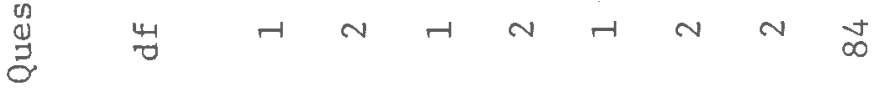

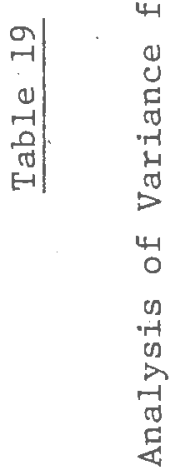

몀

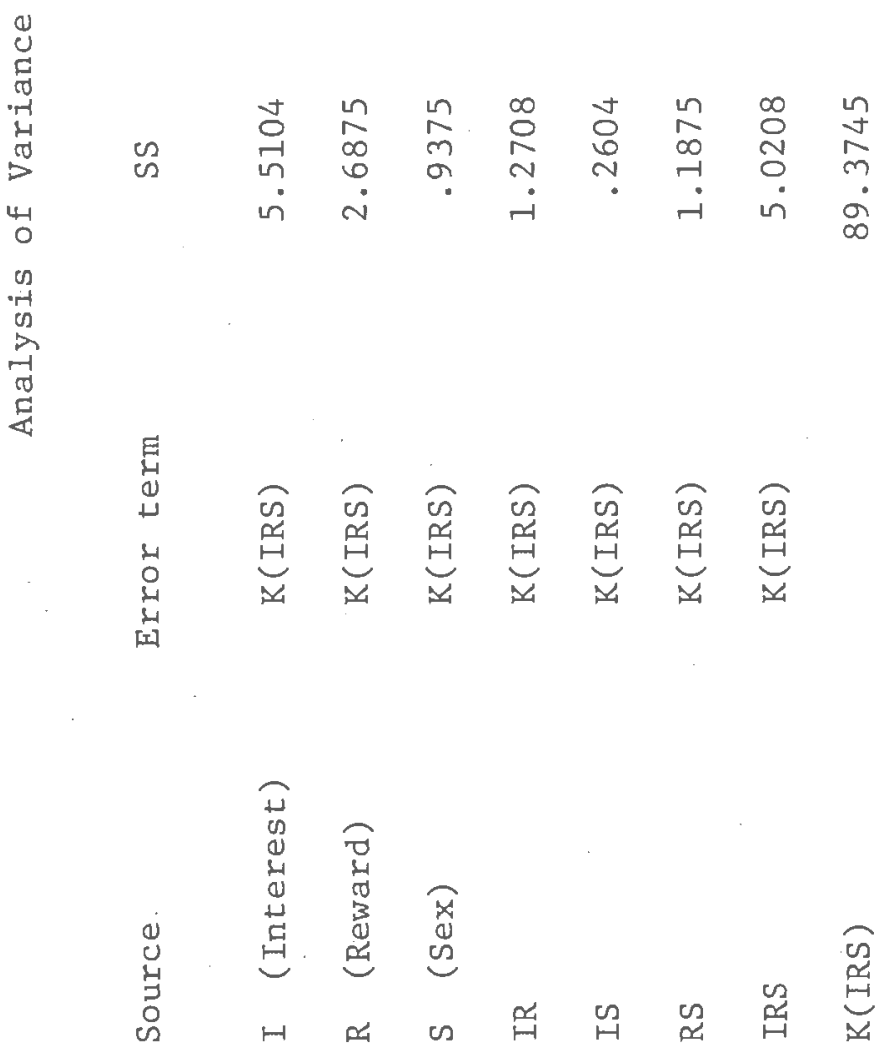




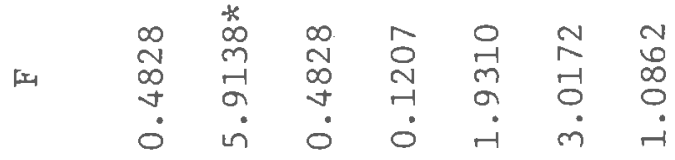

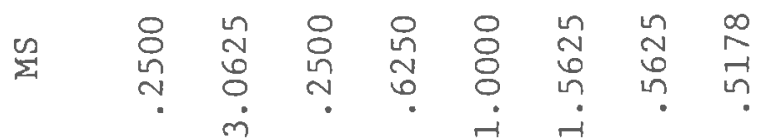

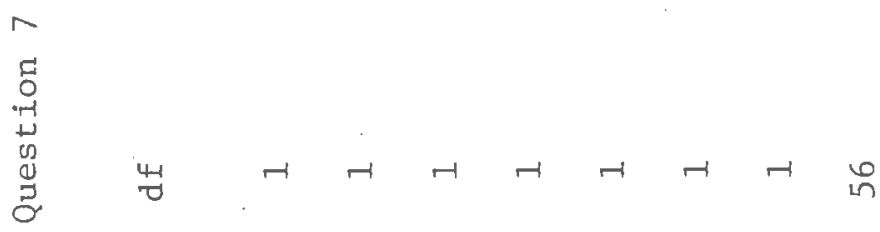

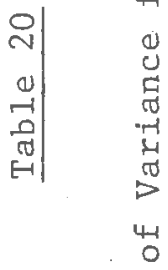

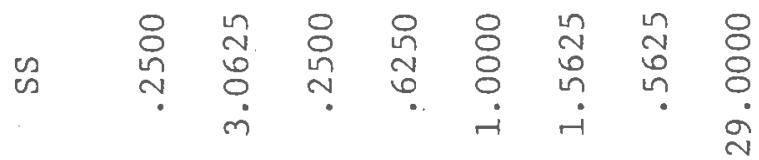

要

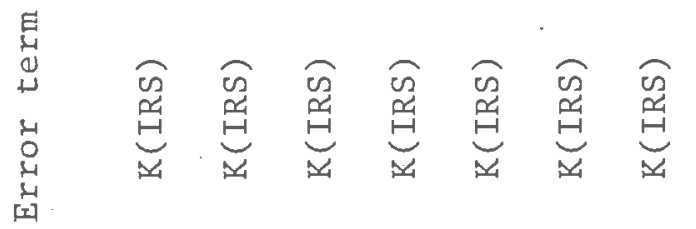

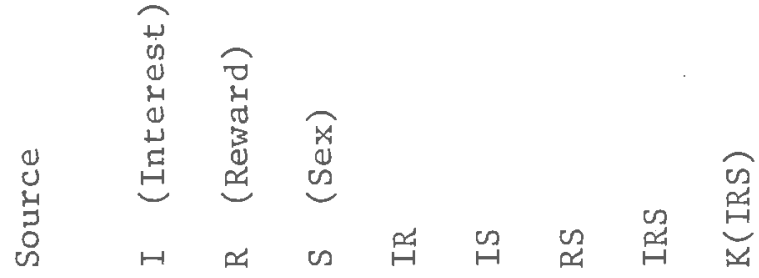


Appendix D

Post-experimental questionnaire 


\section{Post-experimental questionnaire}

1. How do you like the tape? I think the tape is:

Very Good Good Fair Bad Very Bad

2. What do you think this is all about? Waht am I trying to find out?

3. When you get paid for something you like to do, how much do you like to do it when you are not getting paid anymore? I like to do it:

Much More More Just the Same Less Much Less

4. When you get paid for something you do not like to do, how much do you like to do it when you are not getting paid anymore? I like to do it:

Much More More Just the Same Less Much Less

5. Listening to the tape was:

All Work More Work than Play About the Same Amount of Work and Play More Play than Work All Play

6. The tape you heard costs $\$ 1.00$. If you had the money, would you buy the tape in a store? Yes No

7. For self-reward: How did you like paying yourself for listening to the tape? I think paying myself was: Very Good Good Fair Bad Very Bad For external reward: How did you like getting paid for listening to the tape? I think getting paid was:

$$
\text { Very Good. Good Fair Bad Very Bad }
$$

For control: Do you think you should have been paid for listening to the tape: Yes No 
8. If you did this again for pay, would you rather have me decide how much you get paid for listening, or would you rather decide how much you get paid?

I would want you to decide I would like to decide for myself

9. Do you have any questions or things you would like to say? 
Appendix E

Raw data 


\begin{tabular}{|c|c|c|c|c|c|c|c|c|c|c|c|c|c|}
\hline \multirow[b]{2}{*}{ Subject } & \multirow{2}{*}{$\begin{array}{l}\text { Time on } \\
\text { Score }\end{array}$} & \multicolumn{5}{|c|}{ Reward } & \multicolumn{7}{|c|}{ Questionnaire } \\
\hline & & $\mathrm{T} 1$ & $\mathrm{~T} 2$ & T3 & T4 & T5 & Q1 & 3 & 24 & 5 & 26 & 27 & Q8 \\
\hline 1111 & 289 & 10 & 8 & 7 & 10 & 9 & 2 & 3 & 3 & 5 & 1 & 3 & 2 \\
\hline 1112 & 093 & 2 & 2 & 3 & 2 & 2 & 3 & 3 & 4 & 3 & 2 & 4 & 1 \\
\hline 1113 & 820 & 10 & 10 & 10 & 10 & 10 & 2 & 3 & 4 & 4 & 1 & 2 & 1 \\
\hline 1114 & 797 & 2 & 4 & 6 & 8 & 3 & 2 & 4 & 2 & 5 & 1 & 2 & \\
\hline 1115 & 487 & 5 & 7 & 3 & 5 & 4 & 5 & 3 & 3 & 5 & 2 & 1 & \\
\hline 1116 & 311 & 4 & 2 & 6 & 8 & 10 & 3 & 3 & 5 & 4 & 2 & 3 & 1 \\
\hline 1117 & 307 & 9 & 8 & 7 & 10 & 6 & 2 & 3 & 5 & 5 & 1 & 1 & 1 \\
\hline 1118 & 621 & 8 & 10 & 9 & 10 & 9 & 2 & 3 & 3 & 3 & 1 & 2 & 1 \\
\hline 1211 & 485 & 6 & 5 & 8 & 5 & 10 & 2 & 3 & 5 & 4 & 2 & 2 & \\
\hline 1212 & 186 & 8 & 8 & 10 & 9 & 10 & 4 & 3 & 3 & 4 & 2 & 2 & 1 \\
\hline 1213 & 213 & 6 & 5 & 8 & 7 & 10 & 1 & 2 & 4 & 4 & 1 & 2 & \\
\hline 1214 & 920 & 1 & 2 & 3 & 4 & 5 & 2 & 3 & 4 & 3 & 2 & 3 & \\
\hline 1215 & 193 & 5 & 10 & 9 & 5 & 10 & 3 & 3 & 5 & 4 & 2 & 2 & 2 \\
\hline 1216 & 150 & 9 & 10 & 8 & 10 & 7 & 1 & 3 & 3 & 5 & 1 & 2 & \\
\hline 1217 & 135 & 6 & 2 & 1 & 3 & 5 & 2 & 3 & 3 & 5 & 1 & 3 & \\
\hline 1218 & 313 & 6 & 9 & 5 & 2 & 10 & 2 & 3 & 5 & 4 & 1 & 2 & \\
\hline 1121 & 213 & 10 & 8 & 7 & 10 & 9 & 2 & 3 & 4 & 4 & 2 & 2 & \\
\hline 1122 & 434 & 2 & 2 & 3 & 2 & 2 & 1 & 3 & 3 & 5 & 1 & 2 & \\
\hline 1123 & 199 & 2 & 4 & 6 & 8 & 3 & 1 & 3 & 4 & 3 & 1 & 2 & \\
\hline 1124 & 195 & 10 & 10 & 10 & 10 & 10 & 2 & 3 & 3 & 3 & 1 & 1 & \\
\hline 1125 & 376 & 5 & 7 & 3 & 5 & 4 & 2 & 3 & 4 & 4 & 1 & 2 & \\
\hline 1126 & 905 & 4 & 2 & 6 & 8 & 10 & 1 & 3 & 3 & 5 & 1 & 2 & \\
\hline 1127 & 206 & 9 & 8 & 7 & 10 & 6 & 2 & 3 & 4 & 4 & 1 & 3 & \\
\hline 1128 & 796 & 8 & 10 & 9 & 10 & 9 & 2 & 3 & 3 & 3 & 2 & 1 & \\
\hline 1221 & 920 & 5 & 10 & 9 & 5 & 10 & 1 & 1 & 2 & 5 & 1 & 2 & \\
\hline 1222 & 776 & 1 & 2 & 3 & 4 & 5 & 3 & 3 & 1 & 4 & 2 & 2 & \\
\hline 1223 & 191 & 8 & 8 & 10 & 9 & 10 & 2 & 3 & 3 & 4 & 1 & 2 & \\
\hline 1224 & 161 & 9 & 10 & 8 & 10 & 7 & 2. & 4 & 5 & 4 & 1 & 2 & \\
\hline 1225 & 518 & 6 & 5 & 8 & 7 & 10 & 2 & 2 & 3 & 3 & 2 & 2 & \\
\hline 1226 & 920 & 6 & 5 & 8 & 5 & 10 & 2 & 3 & 3 & 3 & 2 & 1 & \\
\hline 1227 & 920 & 6 & 2 & 1 & 3 & 5 & 1 & 2 & 4 & 5 & 2 & 1 & \\
\hline 1228 & 795 & 6 & 9 & 5 & 2 & 10 & 1 & 2 & 3 & 3 & 2 & 1 & \\
\hline 1131 & 717 & 6 & 6 & 6 & 6 & 6 & 2 & 4 & 5 & 3 & 1 & 2 & \\
\hline 1132 & 557 & 1 & 4 & 10 & 8 & 5 & 3 & 4 & 2 & 3 & 2 & 2 & \\
\hline 1133 & 815 & 7 & 8 & 1 & 7 & 10 & 1 & 3 & 4 & 5 & 1 & 2 & \\
\hline 1134 & 164 & 10 & 2 & 0 & 4 & 6 & 2 & 3 & 2 & 3 & 1 & 2 & \\
\hline 1135 & 920 & 4 & 1 & 6 & 7 & 9 & 2 & 4 & 2 & 4 & 2 & 2 & \\
\hline 1136 & 191 & 0 & 2 & 4 & 6 & 8 & 2 & 3 & 4 & 4 & 2 & 2 & \\
\hline 1137 & 395 & 7 & 10 & 9 & 2 & 8 & 2 & 3 & 3 & 3 & 1 & 2 & \\
\hline 1138 & 790 & 4 & 10 & 8 & 1 & 8 & 2 & 3 & 5 & 4 & 2 & 2 & \\
\hline
\end{tabular}


Time on

Subject

1231

1232

1233

1234

1235

1236

1237

1238

2111

2112

2113

2114

2115

2116

2117

2118

2211

2212

2213

2214

2215

2216

2217

2218

2121

2122

2123

2124

2125

2126

2127

2128

2221

2222

2223

2224

2225

2226

2227

2228

\section{Score}

169

486

484

344

212

306

199

187

215

635

371

382

339

135

187

439

920

221

181

139

607

232

319

625

327

354

405

059

330

920

259

920

135

920

129

145

159

192

920

061
$\begin{array}{lllll}\mathrm{T} 1 & \mathrm{~T} 2 & \mathrm{~T} & \mathrm{~T} 4 & \mathrm{~T} 5\end{array}$

$$
\begin{array}{lllll}
2 & 5 & 6 & 7 & 10
\end{array}
$$

$\begin{array}{lllll}10 & 10 & 10 & 10 & 10\end{array}$

$\begin{array}{lllll}8 & 4 & 7 & 10 & 1\end{array}$

$\begin{array}{lllll}3 & 10 & 6 & 8 & 4\end{array}$

$\begin{array}{lllll}10 & 9 & 8 & 7 & 6\end{array}$

$\begin{array}{lllll}1 & 2 & 3 & 4 & 5\end{array}$

$\begin{array}{lllll}10 & 10 & 10 & 10 & 10\end{array}$

$\begin{array}{lllll}10 & 6 & 9 & 4 & 6\end{array}$

$\begin{array}{lllll}5 & 3 & 5 & 9 & 6\end{array}$

$\begin{array}{lllll}4 & 6 & 8 & 10 & 5\end{array}$

$\begin{array}{lllll}8 & 10 & 9 & 10 & 10\end{array}$

$\begin{array}{lllll}6 & 3 & 9 & 8 & 10\end{array}$

$\begin{array}{lllll}10 & 9 & 10 & 9 & 10\end{array}$

$\begin{array}{lllll}2 & 4 & 2 & 3 & 4\end{array}$

$\begin{array}{lllll}5 & 10 & 7 & 8 & 4\end{array}$

$\begin{array}{lllll}2 & 8 & 10 & 6 & 1\end{array}$

$\begin{array}{lllll}3 & 8 & 5 & 8 & 6\end{array}$

$\begin{array}{lllll}3 & 5 & 7 & 9 & 10\end{array}$

$\begin{array}{lllll}6 & 5 & 10 & 8 & 4\end{array}$

$\begin{array}{lllll}5 & 8 & 8 & 8 & 9\end{array}$

$\begin{array}{lllll}4 & 7 & 10 & 7 & 8\end{array}$

$\begin{array}{lllll}9 & 7 & 10 & 8 & 6\end{array}$

$\begin{array}{lllll}3 & 5 & 4 & 6 & 6\end{array}$

$\begin{array}{lllll}2 & 8 & 8 & 2 & 9\end{array}$

$\begin{array}{lllll}5 & 3 & 5 & 9 & 6\end{array}$

$\begin{array}{lllll}8 & 10 & 9 & 10 & 10\end{array}$

$\begin{array}{lllll}10 & 9 & 10 & 9 & 10\end{array}$

$\begin{array}{lllll}6 & 3 & 9 & 8 & 10\end{array}$

$\begin{array}{lllll}2 & 4 & 2 & 3 & 4\end{array}$

$\begin{array}{lllll}2 & 8 & 10 & 6 & 1\end{array}$

$\begin{array}{lllll}4 & 6 & 8 & 10 & 5\end{array}$

$\begin{array}{lllll}5 & 10 & 7 & 8 & 4\end{array}$

$\begin{array}{lllll}4 & 7 & 10 & 7 & 8\end{array}$

$\begin{array}{lllll}9 & 7 & 10 & 8 & 6\end{array}$

$\begin{array}{lllll}3 & 8 & 5 & 8 & 6\end{array}$

$\begin{array}{lllll}5 & 8 & 8 & 8 & 9\end{array}$

$\begin{array}{lllll}6 & 5 & 10 & 8 & 4\end{array}$

$\begin{array}{lllll}3 & 5 & 7 & 9 & 10\end{array}$

$\begin{array}{lllll}3 & 5 & 4 & 6 & 6\end{array}$
Post-experimenta1

Questionnaire

Q1 Q3 Q4 Q5 Q6 Q7 Q8

$\begin{array}{lllllll}2 & 2 & 3 & 3 & 1 & 2 & 1\end{array}$ $\begin{array}{lllllll}2 & 3 & 1 & 2 & 1 & 1 & 1\end{array}$

$\begin{array}{lllllll}2 & 3 & 4 & 4 & 2 & 2 & 1\end{array}$

$\begin{array}{lllllll}2 & 2 & 3 & 4 & 1 & 2 & 1\end{array}$

$\begin{array}{lllllll}2 & 3 & 4 & 5 & 1 & 2 & 1\end{array}$

$\begin{array}{lllllll}3 & 3 & 5 & 4 & 2 & 2 & 1\end{array}$

$\begin{array}{lllllll}1 & 1 & 4 & 4 & 1 & 2 & 1\end{array}$

$\begin{array}{lllllll}2 & 4 & 3 & 2 & 2 & 2 & 1\end{array}$

$\begin{array}{lllllll}4 & 3 & 2 & 4 & 1 & 2 & 1\end{array}$

$\begin{array}{lllllll}2 & 3 & 4 & 4 & 2 & 1 & 1\end{array}$

$\begin{array}{lllllll}2 & 2 & 4 & 3 & 1 & 1 & 2\end{array}$

$\begin{array}{lllllll}2 & 4 & 5 & 4 & 2 & 1 & 2\end{array}$

$\begin{array}{lllllll}2 & 3 & 5 & 3 & 1 & 2 & 2\end{array}$

$\begin{array}{lllllll}1 & 1 & 5 & 3 & 1 & 2 & 1\end{array}$

$\begin{array}{lllllll}2 & 3 & 5 & 3 & 1 & 1 & 2\end{array}$

$\begin{array}{lllllll}3 & 3 & 2 & 2 & 2 & 3 & 1\end{array}$

$\begin{array}{lllllll}1 & 3 & 5 & 5 & 1 & 3 & 1\end{array}$

$\begin{array}{lllllll}3 & 3 & 4 & 2 & 1 & 3 & 2\end{array}$

$\begin{array}{lllllll}2 & 3 & 5 & 5 & 1 & 2 & 2\end{array}$

$\begin{array}{lllllll}2 & 3 & 4 & 3 & 2 & 2 & 2\end{array}$

$\begin{array}{lllllll}3 & 3 & 3 & 3 & 1 & 3 & 1\end{array}$

$\begin{array}{lllllll}2 & 3 & 3 & 3 & 1 & 1 & 2\end{array}$

$\begin{array}{lllllll}2 & 3 & 5 & 3 & 2 & 3 & 1\end{array}$

$\begin{array}{lllllll}3 & 3 & 3 & 5 & 2 & 3 & 1\end{array}$

$\begin{array}{lllllll}3 & 2 & 4 & 5 & 2 & 1 & 1\end{array}$

$\begin{array}{lllllll}2 & 3 & 5 & 3 & 2 & 3 & 1\end{array}$

$\begin{array}{lllllll}2 & 3 & 4 & 2 & 2 & 1 & 1\end{array}$

$\begin{array}{lllllll}3 & 4 & 3 & 3 & 2 & 1 & 1\end{array}$

$\begin{array}{lllllll}1 & 3 & 4 & 3 & 2 & 3 & 1\end{array}$

$\begin{array}{lllllll}1 & 1 & 3 & 4 & 1 & 2 & 1\end{array}$

$\begin{array}{lllllll}3 & 3 & 2 & 2 & 2 & 2 & 2\end{array}$

$\begin{array}{lllllll}1 & 1 & 1 & 5 & 1 & 1 & 1\end{array}$

$\begin{array}{lllllll}3 & 3 & 5 & 5 & 2 & 1 & 1\end{array}$

$\begin{array}{lllllll}2 & 1 & 3 & 4 & 1 & 1 & 1\end{array}$

$\begin{array}{lllllll}1 & 3 & 3 & 5 & 2 & 2 & 1\end{array}$

$\begin{array}{lllllll}4 & 3 & 5 & 3 & 2 & 2 & 1\end{array}$

$\begin{array}{lllllll}3 & 4 & 5 & 3 & 2 & 2 & 2\end{array}$

$\begin{array}{lllllll}2 & 3 & 4 & 3 & 2 & 1 & 2\end{array}$

$\begin{array}{lllllll}2 & 3 & 4 & 4 & 2 & 2 & 1\end{array}$

$\begin{array}{lllllll}3 & 3 & 5 & 4 & 2 & 2 & 1\end{array}$ 


$\begin{array}{ll} & \text { Time on } \\ \text { Subject } & \text { Score }\end{array}$

$\begin{array}{ll}2131 & 137 \\ 2132 & 192 \\ 2133 & 333 \\ 2134 & 125 \\ 2135 & 351 \\ 2136 & 218 \\ 2137 & 074 \\ 2138 & 147 \\ & \\ 2231 & 216 \\ 2232 & 328 \\ 2233 & 157 \\ 2234 & 648 \\ 2235 & 068 \\ 2236 & 362 \\ 2237 & 920 \\ 2238 & 197\end{array}$

\begin{tabular}{|c|c|c|c|c|}
\hline \multicolumn{5}{|c|}{ Reward } \\
\hline T1 & $\mathrm{T} 2$ & T3 & $\mathrm{T} 4$ & T5 \\
\hline 3 & 1 & 7 & 2 & 5 \\
\hline 1 & 9 & 8 & 10 & 3 \\
\hline 10 & 9 & 7 & 6 & 3 \\
\hline 10 & 10 & 10 & 10 & 10 \\
\hline 8 & 8 & 8 & 8 & 8 \\
\hline 0 & 4 & 10 & 7 & 1 \\
\hline 5 & 6 & 7 & 8 & 9 \\
\hline 8 & 8 & 6 & 2 & 4 \\
\hline 2 & 6 & 5 & 8 & 0 \\
\hline 1 & 8 & 4 & 5 & 9 \\
\hline 3 & 9 & 6 & 4 & 8 \\
\hline 0 & 0 & 0 & 0 & 0 \\
\hline 4 & 9 & 1 & 7 & 2 \\
\hline 10 & 7 & 3 & 2 & 8 \\
\hline 10 & 9 & 10 & 9 & 10 \\
\hline 9 & 7 & 5 & 10 & 10 \\
\hline
\end{tabular}

Post-experimental

Questionnaire

Q1 Q3 Q4 Q5 Q6 Q7 Q8

$\begin{array}{lllllll}3 & 3 & 5 & 3 & 2 & 2 & 1 \\ 4 & 3 & 5 & 3 & 2 & 2 & 2 \\ 1 & 2 & 5 & 3 & 1 & 1 & 1 \\ 2 & 3 & 4 & 3 & 2 & 2 & 1 \\ 2 & 3 & 5 & 3 & 1 & 1 & 1 \\ 3 & 3 & 4 & 3 & 2 & 2 & 1 \\ 2 & 3 & 3 & 5 & 2 & 2 & 1 \\ 1 & 2 & 4 & 5 & 2 & 2 & 1\end{array}$

$\begin{array}{lllllll}4 & 4 & 5 & 5 & 2 & 2 & 2\end{array}$

$\begin{array}{lllllll}4 & 3 & 4 & 4 & 2 & 2 & 1\end{array}$

$\begin{array}{lllllll}3 & 2 & 4 & 3 & 2 & 2 & 1\end{array}$

$\begin{array}{lllllll}2 & 3 & 4 & 4 & 1 & 2 & 1\end{array}$

$\begin{array}{lllllll}2 & 3 & 3 & 3 & 1 & 2 & 1\end{array}$

$\begin{array}{lllllll}2 & 3 & 4 & 4 & 1 & 2 & 1\end{array}$

$\begin{array}{lllllll}2 & 3 & 3 & 5 & 2 & 1 & 1\end{array}$ 
Appendix $\mathrm{F}$

Bibliography 
Bibliography

Adams, J. S. Toward an understanding of 1nequity. Journal of Abnormal and Social Psychology, 1963, 67, 422-436.

Adams, J. S. Inequity in social exchange. In L. Berkowitz (Ed.), Advances in experimental social psychology. Vol. 2. New York: Academic Press, 1965.

Allport, G. W. Personality: A psychological interpretation. New York: Holt, $193 \%$.

Atkinson, J. W. An introduction to motivation. Princeton: Van Nostrand, 19

Bandler, R. J., Madaras, G. R., \& Bem, D. J. Self-observation as a source of pain perception. Journal of Personality and Social Psychology, 1968, 9, 205-209.

Bandura, A. Vicarious and self-reinforcement processes. In R. Glaser (Ed.), The nature of reinforcement. New York: Academic Press, 1971. Pp. 228-278.

Bandura, A., Grusec, J. M., Y Menlove, F. L. Some social determinants of self-monitoring reinforcement systems. Journal of Personality and Social Psychology, 1967, 5, 449-455.

Bandura, A., \& Kupers, C. J. Transmission of patterns of selfreinforcement through modeling. Journal of Abnormal and Social Psychology, 1964, 69, 1-9.

Bandura, A., \& Whalen, C. K. The influence of antecedent reinforcement and divergent modeling cues on patterns of self-reward. Journal of Personality and Social Psychology, 1966, 3, 373-382.

Barker, R. G., Dembo, T., \& Lewin, K. Frustration and regression: An experiment with young children. U. of Iowa Studies on Child Welfare, $1941,18,1-314$.

Bem, D. J. Self-perception: An alternative interpretation of cognitive dissonance phenomena. Psychological Review, 1967, 74, 183200 .

Berlyne, D. E. Conflict, arousal, and curiosity. New York: McGrawHil1, 1960.

Calder, B. J., \& Staw, B. M. Self-perception of intrinsic and extrinsic motivation. Journal of Personality and Social Psychology, 1975a, 31, 599-605. 
Calder, B. J., \& Staw, B. M. Interaction of intrinsic and extrinsic motivation: Some methodological notes. Journal of Personality and Social Psychology, 1975b, 31, 76-80.

Crandall, V., Katkovsky, W., \& Cranda11, V. J. Children's beliefs in their own control of reinforcements in intellectual academic achievement situations. Child Development, 1965, 36, 91-109.

Davison, 6 G., \& Valins, S. Maintenance of self-attributed and drugattributed behavior change. Journal of Personality and Social Psychology, $1969,11,25-33$.

de Charms, R. Personal causation: The internal affective determinants of behavior. New York: Academic Press, 1968.

Deci, E. L. Effects of externally mediated reward on intrinsic motivation. Journal of Personality and Social Psychology, 1971, 18, $105-115$.

Deci, E. L. Intrinsic motivation, extrinsic reinforcement, and inequity. Journal of Personality and Social Psychology, 1972, 22, 113-120.

Deci, E. L., Cascio, W. F., \& Krusell, J. Cognitive evaluation theory and some comments on the Calder and Staw critique. Journal of Personality and Social Psychology, 1975, 31, 81-85.

Festinger, L. A theory of cognitive dissonances. Evanston, I11.: Row, Peterson, 1957.

Festinger, L., \& Carlsmith, J. M. Cognitive consequences of forced compliance. Journal of Abnormal and Social Psychology, 1959, 58, 203-211.

Ford, J. D., \& Foster, S. L. Extrinsic incentives and token-based programs: A reevaluation. American Psychologist, 1976, 31 , $87-90$.

Goldfried, M., \& Merbaum, M. (Eds.) Behavior change through self contro1. New York: Holt, Rinehart, and Winston, 1973.

Harlow, H. F. Learning and satiation of response in intrinsically motivated complex puzzle performance by monkeys. Journal of Comparative Physiological Psychology, 1950, 43, 289-294.

Heider, F. The psychology of interpersonal relations. New York: Wiley, 1953.

Hunt, J. Intrinsic motivation and its role in psychological develop- ment. In D. Levine (Ed.), Nebraska Symposium on motivation (Vol. 13). Lincoln: U. Nebraska Press, 1965. 
Johnson, T. J., Feigenbaum, R., \& Weibey, M. Some determinants and consequences of the teacher's perception of causality. Journal of Educationa1 Psychology, 1964, 55, 237-246.

Jones, E. E., \& Davis, K. E. From acts to dispositions: The attribution process in person perception. In L. Berkowtiz (Eds), Advances in experimental social psychology (Vol. 2). New York: Academic Press, 1965.

Jones, E. E., Kanouse, D. E., Kelley, H. H., Nisbett, R. E., Valins, S., \& Weiner, B. Attribution: Perceiving the causes of behavior. Morristown, N. J.: General Learning Press, 1972.

Kanfer, F. H. Influence of age and incentive conditions on children's self-rewards. Psychological Reports, 1966, 19, 263-274.

Kanfer, F. H. Self-regulation: Research, issues, and speculations. In C. Neuringer \& J. W. Michael (Eds.), Behavior modification in clinical psychology. New York: Appleton, 1970 .

Kanfer, F. H., \& Duerfeldt, P. H. Effects of pretraining on selfevaluation and self-reinforcement. Journal of Personality and Socia1 Psychology, 1967, 2, 164-168.

Kanfer, F. H., \& Duerfeldt, P. H. Comparison of self-reward and selfcriticism as a function of types of prior external reinforcement. Journal of Personality and Social Psychology, 1968, ㅁ, 261-268.

Kanfer, F. H., Duerfeldt, P. H., Y LePage, A. L. Stability of patterns of self-reinforcement. Psychological Reports, 1969, 24, $663-670$.

Kanfer, F. H., \& Marston, A. R. Determinants of self-reinforcement in human learning. Journal of Experimental Psychology, 1963, 66, 245-254.

Kazdin, A. E., \& Bootzin, R. R. The token economy: An evaluative review. Journal of Applied Behavior Analysis, 1972, 5, 1-30.

Kelley, H. H. Attribution theory in social psychology. Nebraska symposium on motivation, $1967,14,192-241$.

Kiesler, C. A., Nisbett, R. E., \& Zanna, M. P. On inferring one's beliefs from one's behavior. Journal of Personality and Social Psychology, 1969, 11, 321-327.

Kiesler, C. A., \& Sakamura, J. A test of a model for commitment. Journal of Personality and Social Psychology, 1966, $3,349-353$.

Krasner, L. On the death of behavior modification: Some comments from a mourner. American Psychologist, 1976, 31, 387-388. 
Kruglanski, A. W., Alon, S., \& Lewis, T. Retrospective misattribution and task enjoyment. Journal of Experimental Social Psychology, $1972,8,493-501$.

Kruglanski, A. W., Friedman, I., \& Zeevi, G. The effects of extrinsic incentive on some qualitative aspects of task performance. Journal of Personality, 1971, 39, 606-617.

Kruglanski, A. W., Riter, A., Amitai, A., Margolin, B., Shabtai, L., \& Zaksh, D. Can money enhance intrinsic motivation?: A test of the content-consequence hypothesis. Journal of Personality and Social Psychology, 1975, 31, 744-750.

Lefcourt, H. M. Internal versus external control of reinforcement: A review. Psychological Bulletin, 1966, 65, 206-220.

Lepper, M. R., \& Greene, D. Turning play into work: Effects of adult surveillance and extrinsic rewards on children's intrinsic motivation. Journal of Personality and Social Psychology, 1975, 31, $479-486$.

Lepper, M. R., \& Greene, D. On understanding "overjustification": A reply to Reiss and Sushinsky. Journal of Personality and Social Psychology, 1976, 33, 25-35.

Lepper, M. R., Greene, D., \& Nisbett, R. E. Undermining children's intrinsic interest with extrinsic rewards: A test of the overjustification hypothesis. Journal of Personality and Social Psychology, 1973, 28, 129-137.

Levine, F. M., \& Fasnacht, G. Token rewards may lead to token learning. American Psychologist, 1974, 29, 817-820.

Levine, F. M., \& Fasnacht, G. Levine and Fasnacht reply to Ford and Foster. American Psychologist, 1976, 31, 90-92.

Lovitt, T. C., \& Curtiss, K. A. Academic response rate as a function of teacher and self-imposed contingencies. Journal of Applied Behavior Analysis, 1969, 2, 49-53.

McCullers, J. C., \& Martin, J. A. G. A reexamination of the role of incentive in children's discrimination learning. Child Development, $1971,42,837-837$.

Marston, A. R. Personality variables related to self-reinforcement. Journal of Psychology. 1964a, 58, 169-175.

Marston, A. R. Variables affecting incidence of self-reinforcement. Psychologica1 Reports, 1964b, 14, 879-884. 
Marston, A. R. Self-reinforcement. The relevance of a concept in analogue research in psychoterapy. Psychotherapy: Theory, Research and Practice, 1965, 2, 1-5.

Marx, M. H. Learning: Processes. New York: Macmillan, 1969.

Masters, J. C., \& Mokros, J. R. Self-reinforcement processes in children. In H. Reese (Ed.), Advances in child development and behavior (Vol. 9). New York: Academic Press, 1974.

Michotte, A. The perception of causality. New York: Basic Books, 1963.

Miller, L. F., \& Estes, B. W. Monetary reward and motivation in discrimination learning. Journal of Experimental Psychology, 1961, 61, 501-504.

Mische1, W. Toward a cognitive social learning reconceptualization of personality. Psychological Review, 1973, 80, 252-283.

Montessori, M. The Montessori method: Scientific pedegogy as applied to child education. In A. George (Trans.), The children's house: With additions and revisions. New York: Frederick Stokes, 1912. Originally published in 1909 .

Murray, E. J. Motivation and emotion. Englewood Cliffs, N. J.: Prentice Hal1, 1964.

Nisbett, R. E., \& Schachter, S. Cognitive manipulation of pain. Journal of Experimental Social Psychology, 1966, 2, 227-236.

Nisbett, R. E., \& Valins, S. Perceiving the causes of one's own behavior. In Jones et al (Eds.), Attribution: Perceiving the causes of behavior. Morristown, N. J.: General Learning Press, 1972.

Notz, W. W. Work motivation and the negative effects of extrinsic rewards: A review with implications for theory and practice. American Psychologist, 1975, 30, 884-891.

O'Leary, K. D., \& Drabman, R. Token reinforcement programs in the classroom: A review. Psychological Bulletin, 1971, 75, 379-398.

Oziel, J. L., \& Berwick, P. T. Effects of feedback on self-reinforcement behavior in relation to self-acceptance. Psychological Reports, 1974, 34, 1039-1044.

Piaget, J. The origins of intelligence in children. (M. Cook, Trans.) New York: International U. Press, 1952. (Originally published in 1936). 
Premack, D. Catching up with common sense or two sides of a generalization: Reinforcement and punishment. In R. Glaser (Ed.), The nature of reinforcement. New York: Academic Press, 1971. Pp. 121-150.

Reiss, S., \& Sushinsky, L. W. Overjustification, competing responses, and the acquisition of intrinsic interest. Journal of Personality and Social Psychology, 1975, 31, 1,116-1,125.

Reschly, D. Consistency of self-reinforcement rates over different tasks; and sex, task success, and ability as terminants of rates of self-reinforcement. Psychological Record, 1973, 23, 237-242.

Ross, M. Salience of reward and intrinsic motivation. Journal of Personality and Social Psychology, 1975, 32, 245-254.

Ross, M., Karniol, R., and Rothstein, M. Reward contingency and intrinsic motivation in children: A test of the delay of gratification hypothesis. Journal of Personality and Social Psychology, $1976,33,442-447$.

Ross, L. D., Rodin, J., \& Zimbardo, P. G. Toward an attribution therapy: The reduction of fear through induced cognitiveemotional misattribution. Journal of Personality and Social Psychology, 1969, 12, 279-288.

Rotter, J. B. Social learning and clinical psychology. Englewood Cliffs, N. J.: Prentice-Hall, 1954.

Schachter, S., \& Singer, J. E. Cognitive, social and physiological determinants of emotional states. Psychological Review, 1962, $\underline{69}, 379-399$.

Seligman, M. E. P. Helplessness. San Francisco, W. H. Freeman, 1975.

Sidman, M. Tactics of scientific research. New York: Basic Books, 1960.

Skinner, B. F. Science and human behavior. New York: Macmillan, 1953.

Sobell, M. On doing time. New York: Scribner's, 1974 .

Spence, J. T. Do material rewards enhance the performance of lowerclass children? Child Development, 1971, 42, 1461-1470.

Switzky, H. N., \& Haywood, C. H. Motivational orientation and the relative efficacy of self monitored and externally imposed reinforcement systems in children. Journal of Personality and Social Psychology, $1974,30,360-366$. 
Thoresen, C. E., \& Mahoney, M. J. Behavioral self control. New York: Holt, Tinehart, \& Winston, 1974.

Three Dog Night: Their greatest hits. New York: ABC Records, 1974.

Valins, S. \& Ray, A. A. Effects of cognitive desensitization of avoidance behavior. Journal of Personality and Social Psychology, $1967,7,345-350$.

Woodworth, R. S. Dynamic psychology. New York: Columbia U. Press, 1918. 